\title{
Study of the thermal behavior of a synchronous motor with permanent magnets
}

\author{
Souhil Seghir-Oualil ${ }^{1,3}$, Souad Harmand ${ }^{1,3, a}$, Daniel Laloy ${ }^{2,3}$ and \\ OLIVIER PhilLiparT ${ }^{2,3}$ \\ 1 Laboratoire de Mécanique et Énergétique, Université de Valenciennes et du Hainaut-Cambrésis, Le Mont Houy, \\ 59313 Valenciennes Cedex 9, France \\ 2 Jeumont Electric, BP 189, 59573 Jeumont, France \\ 3 Centre National de Recherche Technologique, Futurelec 2, France
}

Received 9 July 2008, Accepted 30 November 2009

\begin{abstract}
The present study deals with the thermal behavior of an electric motor used in naval propulsion. A permanent three-dimensional model based on a nodal approach was developed to predict the thermal behavior of the machine in permanent state. The various heat transfer modes playing a role (mainly the conduction, the convection and the mass transfer) are taken into account. The three dimensional developed model provides information (in terms of heat fluxes or temperatures) for the whole machine. A parametric study using this model is carried out aiming at two objectives. The first one consists in an evaluation of the influence of several factors on the temperature distribution. The second one aims at obtaining the inception of the thermal optimization and evaluating the more efficient cooling techniques or solutions.

Key words: Convective heat transfer / electrical synchronous motor / cooling enhancement / infrared thermography / thermal modeling

Résumé - Étude thermique d'un moteur synchrone à aimants permanents. On présente dans ce travail le comportement thermique d'un moteur électrique destiné à la propulsion navale. Une modélisation tridimensionnelle de la machine a été réalisée à partir d'une approche de type nodal dans le but de prédire son comportement thermique en régime de fonctionnement stabilisé. L'ensemble des modes de transferts (conduction, convection, transfert de masse) a été pris en compte et permet de dresser des cartographies de la machine en termes de température et de flux de chaleur. Une étude de sensibilité a été réalisée à partir de cette modélisation et a permis d'une part de mettre en évidence l'influence des paramètres de fonctionnement de la machine sur la répartition de la température et d'autre part de dégager des voies permettant l'amélioration de la dissipation des échauffements dont elle est le siège.
\end{abstract}

Mots clés : Échange convectif / moteur électrique synchrone / amélioration du refroidissement / thermographie infrarouge / modélisation thermique

\section{Introduction}

Since the electric motors beginning and the will to increase their performances, such machines are confronted to the heating problems. Some parts of these machines can reach significant and disallowed temperatures entailing their deterioration. These parts are in particular the winding insulators, the bearings or the magnets. These latters are particularly sensitive to high temperatures since they can loose a part of their magnetization when they are exposed to a too high temperature. In order to preserve the optimal conditions ensuring the good operation of the motor, it is imperative to well understand and control the

\footnotetext{
a Corresponding author:

souad.harmand@univ-valenciennes.fr
}

thermal behavior of these motors. This good understanding needs the ideal design of coolers to ensure the operating temperatures not exceed the acceptable limits of used materials.

The synchronous motors operation is based on the existence of a turning magnetic field which can be obtained by the circulation of a controlled current into stator winding. Only a part of the electric power is converted into mechanical power, the other part entails a warm up of the machine and constitutes the losses to be evacuated. To predict the lifetime of an electric motor and to improve its efficiency, it is necessary to carefully investigate its thermal design in order to determine the best cooling solutions.

In this work, a three-dimensional numerical code based on a nodal approach was developed in order to 
Nomenclature

\begin{tabular}{|c|c|c|}
\hline$a$ & thermal diffusivity $=\lambda / \rho c_{\mathrm{p}}$ & $\mathrm{m}^{2} \cdot \mathrm{s}^{-1}$ \\
\hline$c_{\mathrm{p}}$ & specific heat & $\mathrm{J} \cdot \mathrm{kg}^{-1} \cdot \mathrm{K}^{-1}$ \\
\hline$D$ & rotor diameter & $\mathrm{m}$ \\
\hline$e$ & air-gap thickness & $\mathrm{m}$ \\
\hline$e_{\text {eq }}$ & equivalent thickness $=2 S_{\mathrm{mo}} / P_{\mathrm{mo}}$ & $\mathrm{m}$ \\
\hline G & thermal conductance & W.K $\mathrm{K}^{-1}$ \\
\hline$g$ & gravity & $9.81 \mathrm{~m} \cdot \mathrm{s}^{-2}$ \\
\hline$H$ & fin width & $\mathrm{m}$ \\
\hline$h$ & heat transfer coefficient & $\mathrm{W} \cdot \mathrm{K}^{-1} \cdot \mathrm{m}^{-2}$ \\
\hline$L$ & length of the rotor & $\mathrm{m}$ \\
\hline$P$ & perimeter & $\mathrm{m}$ \\
\hline$Q_{\mathrm{m}}$ & mass flow rate & $\mathrm{kg} \cdot \mathrm{s}^{-1}$ \\
\hline$R$ & radius & $\mathrm{m}$ \\
\hline$S$ & surface & $\mathrm{m}^{2}$ \\
\hline$T$ & temperature & ${ }^{\circ} \mathrm{C}$ \\
\hline$Z$ & axial coordinate & $\mathrm{m}$ \\
\hline$U, V$ & velocity & $\mathrm{m} . \mathrm{s}^{-1}$ \\
\hline \multicolumn{3}{|c|}{ Dimensionless numbers } \\
\hline$N u$ & Nusselt number & \\
\hline $\operatorname{Pr}$ & Prandtl number $=\mu c_{\mathrm{p}} / \lambda$ & \\
\hline$R a$ & Rayleigh number $=g \beta\left(T_{\mathrm{p}}-T_{\infty}\right) D_{\mathrm{i}}^{3} / \mathrm{a} \nu$ & \\
\hline$R e_{\mathrm{a}}$ & axial Reynolds number $=2 e U_{\mathrm{a}} / \nu$ & \\
\hline$R e_{\mathrm{r}}$ & Reynolds number $=R_{\mathrm{c}} U_{\infty} / \nu$ & \\
\hline$T a$ & Taylor number $=2 e^{0.5} R_{\mathrm{ro}}^{1.5} \omega / \nu$ & \\
\hline \multicolumn{3}{|c|}{ Greek symbols } \\
\hline$\alpha$ & angle & $\mathrm{rad}$ \\
\hline$\beta$ & thermal coefficient of volumetric expansion & $\mathrm{K}^{-1}$ \\
\hline$\phi$ & heat flux & $\mathrm{W}$ \\
\hline$\lambda$ & thermal conductivity & $\mathrm{W} \cdot \mathrm{K}^{-1} \cdot \mathrm{m}^{-1}$ \\
\hline$\eta$ & geometrical report/ratio of form $=R_{\mathrm{st}} / R_{\mathrm{ro}}$ & \\
\hline$\mu$ & dynamic viscosity & $\mathrm{kg} \cdot \mathrm{m}^{-1} \cdot \mathrm{s}^{-1}$ \\
\hline$\nu$ & kinematic viscosity & $\mathrm{m}^{2} \cdot \mathrm{s}^{-1}$ \\
\hline$\rho$ & density & $\mathrm{kg} \cdot \mathrm{m}^{3}$ \\
\hline$\omega$ & rotational speed & rad.s ${ }^{-1}$ \\
\hline \multicolumn{3}{|c|}{ Subscripts and superscripts } \\
\hline $\mathrm{a}$ & axial & \\
\hline c & frame & \\
\hline cond & conduction & \\
\hline conv & convection & \\
\hline flui & fluidic & \\
\hline i & interior & \\
\hline $\mathrm{m}$ & averaged & \\
\hline mo & wet & \\
\hline op & optimal & \\
\hline $\mathrm{p}$ & wall & \\
\hline $\mathrm{r}$ & rotational & \\
\hline ro & rotor & \\
\hline st & stator & \\
\hline$\infty$ & ambient or far from the wall & \\
\hline
\end{tabular}




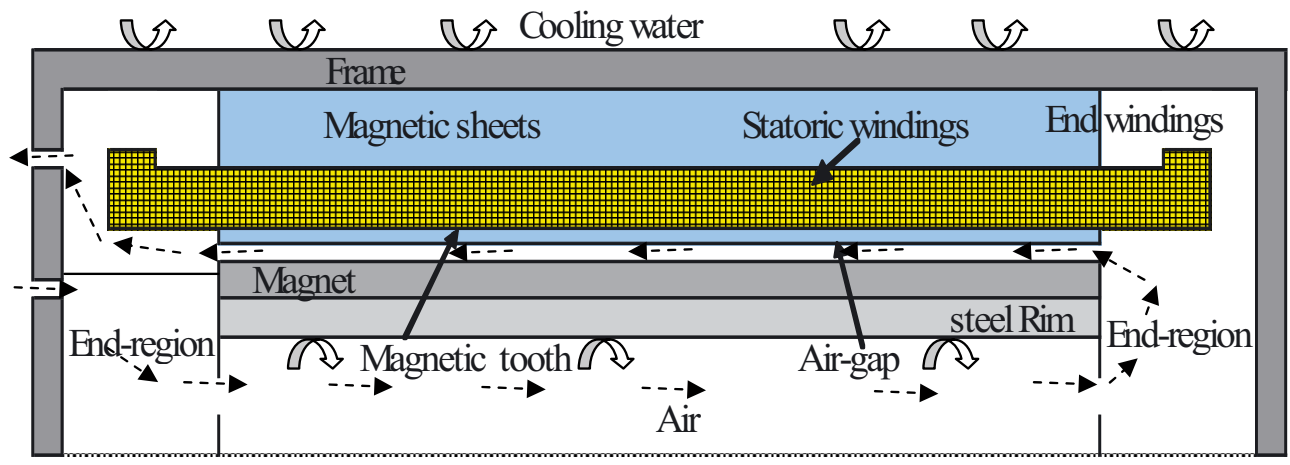

Fig. 1. Axial cross-section of the motor.

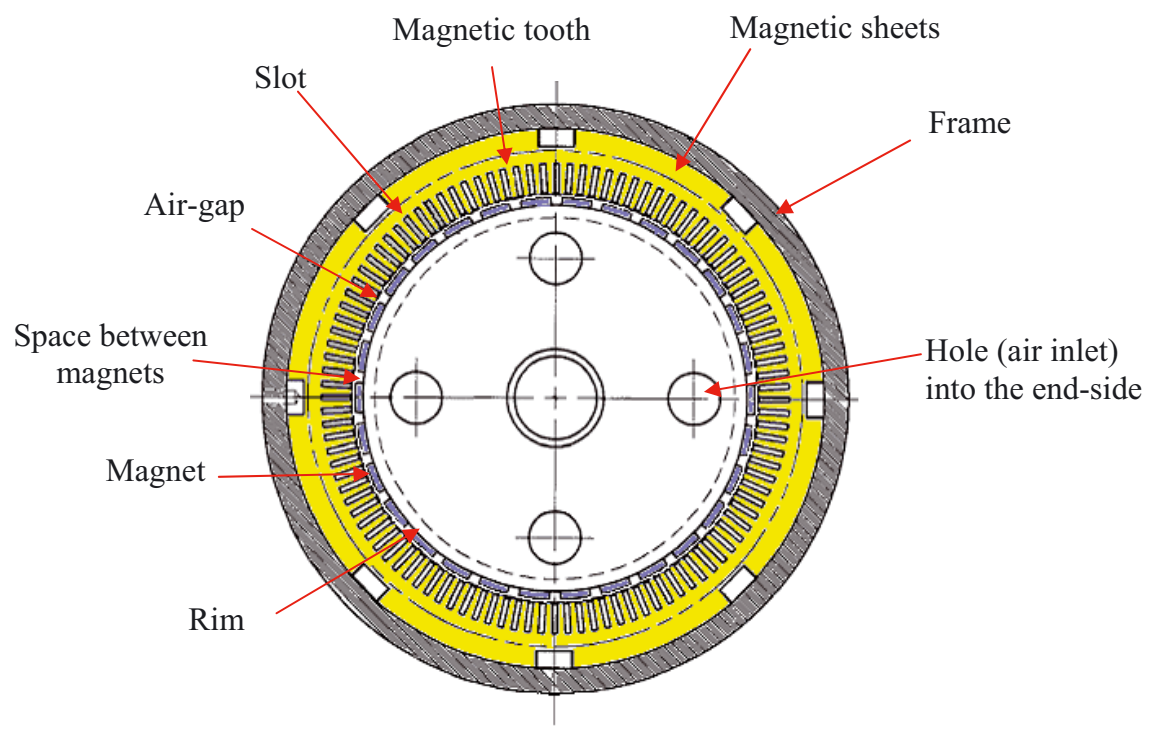

Fig. 2. Radial view of the motor.

better apprehend the thermal behavior of the machine. The model provides information about the thermal behavior of the motor letting obtain the whole machine temperature.

\section{Description of the studied engine}

Figures 1 and 2 present respectively an axial and a radial cross-section of the studied engine. This kind of motor is used for the naval propulsion. It is mainly composed by two parts: the rotor (rotating part) and the stator (static part) separated by the very thin air-gap (some millimeters). The stator is made by a succession of steel sheets insulated electrically. It is at the origin of important electromagnetic dissipations. These sheets are axially grooved and the slots are equally distributed following the angle. In these latters, insulated copper conductors are inserted to compose the statoric winding. These conductors are rolled up around the magnetic teeth. The exceeding insulated copper part is called the end-winding. The rotor consists in an empty rotating cylinder placed inside the stator and maintained with two side-plates. Permanent magnets equally distributed with the angle are stuck at its periphery. The rotor and stator are placed together into a frame made of steel. The latter aims at protect and maintain the various parts of the machine.

This high power motor is of a great compactness. The most part of the absorbed electric power is converted into mechanical power and drives the motor into rotation. The residual part (losses) of this energy must be evacuated since it entails the heating up of the machine. These losses constituting the heating sources are mainly known as the Joule effect in the windings of the stator, and the iron losses located mainly in stator sheets and very partially into the magnets of the rotor. The cooling of this electrical machine is ensured both by a very low airflow rate into the empty rotor and by the cooling water which flows at its external periphery.

\section{Numerical model}

Thermal designing needs a good knowledge of the phenomena playing a role. The predominant phenomena occurring in the studied electric motor are: the conductive heat exchanges between the various solids parts of the 
machine, the convective heat exchanges between the walls and the fluids, and also the heat exchanges due to the airflow. Due to the low temperature levels, radiation can be neglected. A nodal approach was chosen to model the thermal behavior of this engine. This method, rather simple to implement in steady state operation, lets quickly calculate the temperature field into the whole machine using a reasonable node networks and a reduced storage capacity.

To establish a nodal thermal model of this synchronous motor, a nodal network of the machine was performed and divides the machine into numerous solid and fluid isotherm blocks which are represented by a node. The fluid area connections are either represented by convective thermal resistances, either by fluidic thermal resistances, either both. Conduction only occurs between solid area nodes. Each connection between neighbor solid nodes is represented by a conductive thermal resistance.

\subsection{Nodal analysis}

The nodal method was initially developed for the electrical network analysis, and was quickly applied successfully to thermal systems [1-3]. This approach consists in dividing the system in a certain number of elementary volumes assumed as isotherm and represented by a node. Heat transfers between these nodes are modeled using thermal conductance, heat or sink sources and/or imposed temperature conditions. Then this method consists on the one hand to represent the various elements of the system (rotor, stator, airflow... ) by isothermal nodes in order to build an equivalent network and on the other hand to identify the various heat transfer modes occurring in this network. After having discretized the domain, the equations of heat transfers associated to each node can be written. These equations represent the energy conservation within the element of volume related to a given node. Thus, this energy balance expressed the equality between the internal energy variation (within the considered volume connected to this node) and the energy exchanged with other nodes using the various heat transfer modes. In steady state, for a node $(i)$ connected with the nodes $(j)$, the heat balance can then be written as:

$$
\begin{aligned}
\sum_{j \neq i} G_{i j}^{\text {cond }}\left(T_{j}-T_{i}\right)+ & \sum_{j \neq i} G_{i j}^{\text {conv }}\left(T_{j}-T_{i}\right) \\
& +\sum_{j \neq i} G_{i j}^{\mathrm{fui}}\left(T_{j}-T_{i}\right)+\phi_{i}=0
\end{aligned}
$$

In this equation $\phi_{i}$ referred to an internal heat source, and $G_{i j}^{\text {cond }}, G_{i j}^{\text {conv }}, G_{i j}^{\text {flui }}$ referred respectively to the conductive, convective and fluidic (due to the airflow) conductances between the node $i$ and the nodes $j . T_{i}$ and $T_{j}$ referred to the temperature of the node $i$ or $j$. The radiative exchanges are neglected due to the nature of the walls and the temperature levels into the motor. Applying this equation to the whole machine and using a matrix form, (1) can then be written:

$$
\left[G_{i j}\right] \times\left[T_{i}\right]=\left[\phi_{i}\right]
$$

In this last equation, $\left[G_{i j}\right]$ is the matrix of the thermal conductances, $\left[T_{i}\right]$ is the temperature vector, and $\left[\phi_{i}\right]$ is the heat source/sink vector. The temperatures field $\left(\left[T_{i}\right]\right)$ into the whole motor can then easily be obtained since:

$$
\left[T_{i}\right]=\left[G_{i j}\right]^{-1} \times\left[\phi_{i}\right]
$$

The specific computer code was developed for modeling of the thermal behavior. The resolution is carried out in two steps. The first step consists in the (nodal) network building and the calculation of both the thermal conductances and the heat sources. The second step consists in the inversion of the matrix to obtain the temperatures.

\subsection{Model description}

An electric machine constitutes a complex thermal system, but presents several symmetries and periodicities which were used in the model to decrease the node number. Table 1 gathers the various geometric elements as well as various heat flux and conductances used in the model.

Earlier works on the rotating machines carried out by Bertin [4] and Vasilescu [5] showed it was possible to only study an elementary sector instead of the whole machine. Using geometrical considerations, only $1 / 108$ th of the stator and $1 / 30$ th of the rotor were modeled. These two parts are then coupled using the mathematical coupling suggested by Bertin [4]. As shown in Figures 3 and 4, each elementary pattern of the stator is composed with a slot, a magnetic tooth, a portion of the magnetic sheets and the frame. For the rotor, the studied pattern consists in a magnet, an air space between magnets and considerations, the studied structure presented in Figure 3 can be divided in 7 independent node blocks.

\subsection{Boundary conditions}

On the radial plane presented in Figure 3, convective boundary conditions are applied to the internal and external surfaces (inner air and water). For side surfaces, Neumann's type boundary conditions $(\partial T / \partial n=0)$ are applied to take into account the symmetries. The temperature of the cooling water $\left(T_{\text {water }}\right)$ is $40{ }^{\circ} \mathrm{C}$ whereas the air temperature at the rotor inlet $\left(T_{\text {air }}\right)$ is $45^{\circ} \mathrm{C}$. An adiabatic condition is applied at the two end-sides (in the axial direction) of the machine.

\subsection{Thermal conductivities, losses and convective heat transfer coefficients}

The materials constituting the different parts of the electrical motor, and their thermal conductivities are gathered in Table 2. In the studied motor, the windings need a specific attention since they are not isotropic materials and are subjected to very severe thermal constraints. These windings are made of copper, enamel, 
Table 1. Expressions used for $G_{i j}$.

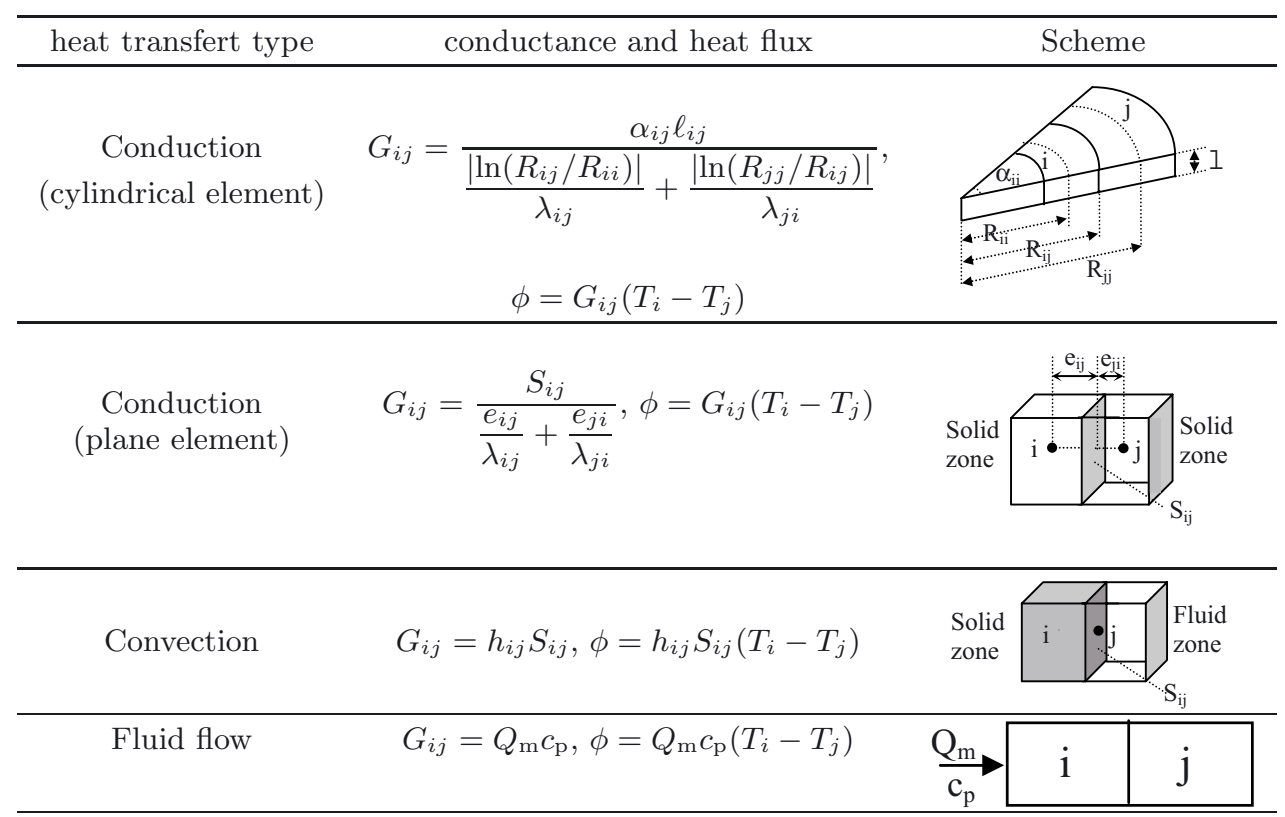

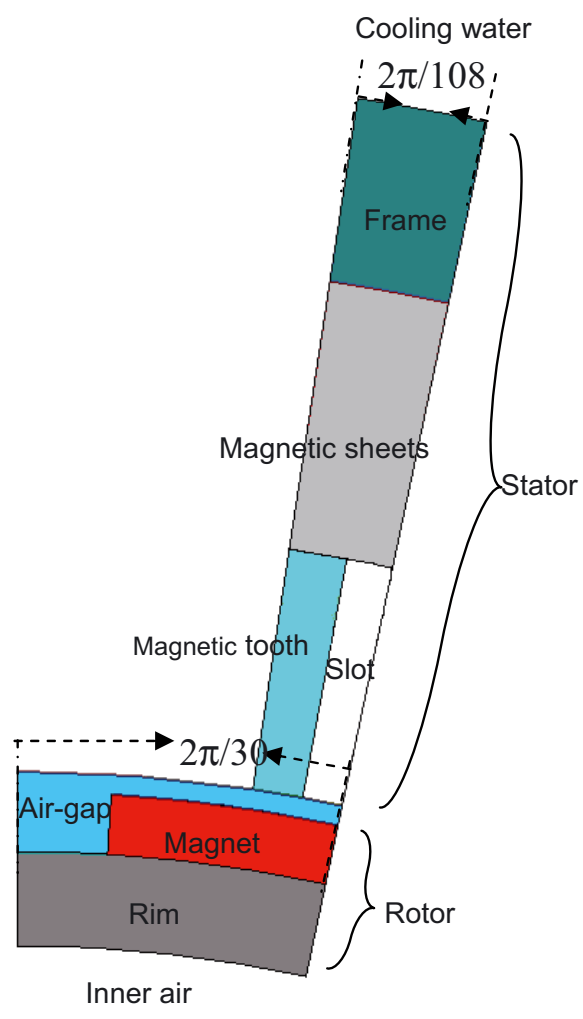

Fig. 3. 2D Model for the stator and the rotor.

epoxy resin, Dacron ${ }^{\circledR}$ and glass fiber. Their thermal resistances are determined by considering they are a 3D thermal network (serial and parallel resistance association in the radial, ortho-radial and axial direction) of their different composing materials. In the radial and ortho-radial direction, the insulating materials govern the values of equivalent thermal conductivities whereas this value is

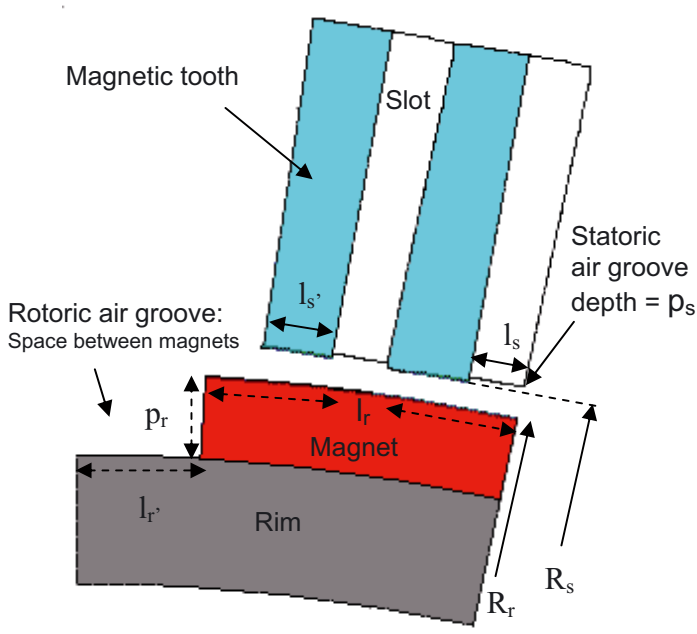

Fig. 4. Radial cross-section of the air-gap (close up).

governed by the high conductivity of the copper in the axial direction. The values obtained for the thermal conductivities in the three directions are gathered in Table 3.

During operation, a significant number of losses are generated in the various components. Table 4 gathers their localizations as well as their experimental values. The determination of the convective thermal conductances needs the knowledge of the convective heat transfer coefficients. These coefficients are often determined using correlations available in literature. Most of the studies $[4,5]$ about the modeling of the electric motors suggest to take into account the convection in a very simplified way, by imposing a constant heat transfer on all the wall in contact with the fluid. 
Table 2. Materials used and their physical properties.

\begin{tabular}{|c|c|c|}
\hline Parts & Material & Thermal conductivity $\left(\mathrm{W} \cdot \mathrm{m}^{-1} \cdot \mathrm{K}^{-1}\right)$ \\
\hline Windings & Copper & 380 \\
\hline taping & enamel, glass fiber, epoxy resin & 0.15 \\
\hline turn insulation & glass fiber, mica, epoxy resin & 0.15 \\
\hline Ribbon & Dacron ${ }^{\circledR}$, epoxy resin & 0.15 \\
\hline spacer & glass fiber, epoxy resin & 0.15 \\
\hline Impregnation & epoxy resin & 0.15 \\
\hline Stick & & 0.15 \\
\hline Magnets & $\mathrm{NdFeB}$ or frit $\mathrm{SmCo}$ & 9 \\
\hline Frame, Rim & Steel & 50 \\
\hline Magnetic sheets & $\begin{array}{l}\text { Steel, electric insulation } \\
\text { on both faces }\end{array}$ & $\begin{array}{cc}25 \text { (in the radial } & 2 \text { (in the axial } \\
\text { cross section) } & \text { cross section) }\end{array}$ \\
\hline
\end{tabular}

Table 3. Final windings (windings+insulation) thermal conductivity.

\begin{tabular}{cccc}
\hline Direction & Radial & Ortho-radial & Axial \\
\hline $\begin{array}{c}\text { Thermal conductivity } \\
\left(\mathrm{W} \cdot \mathrm{m}^{-1} \cdot \mathrm{K}^{-1}\right)\end{array}$ & 0.59 & 0.71 & 237 \\
\hline
\end{tabular}

Table 4. Location and values of the losses in the motor.

\begin{tabular}{lc}
\hline Location of the losses & losses (W) \\
\hline Iron losses into the statoric windings (air-gap side) & 17550 \\
Iron losses into the statoric windings (frame side) & 15150 \\
Iron losses into the end-windings & 6100 \\
Iron losses into the teeth & 21000 \\
Iron losses into the frame & 13300 \\
Losses into the magnets & 3000 \\
\hline Total losses & 76100 \\
\hline
\end{tabular}

Keeping in mind that the engine frame is underwater and that airflow flows inside an empty rotor as well as in its air-gap, 4 convective heat transfer coefficients have to be identified: into the rotor, into the air-gap, at the periphery of the frame and onto the two internal face of the end-regions.

\subsubsection{Air in the air-gap}

The studied air-gap consists in a cylinder rotating inside a static one with a ribbed air-gap where air flows axially. The rotor has 30 axial slots equally spaced on its external surface (depth: $18.1 \mathrm{~mm}$, width: $28 \mathrm{~mm}$ ) whereas the stator has 108 axial slots equally distributed on its inner circumference (depth: $0.8 \mathrm{~mm}$, width: 12.3) (see Fig. 4). In such a configuration, the flow and the convective heat transfer are both controlled by the Taylor number and the axial Reynolds number respectively characterizing the rotation and the airflow effects. Several authors proposed correlations giving the Nusselt number in an air-gap with an axial airflow [6-10]. These correlations obtained experimentally were often carried out on quite specific engines. So, with these correlations, it is difficult to accurately identify the heat transfer coefficients in the configuration investigated here. Initially, the correlation of Tachibana and Fukui [6] is used since it is the less restrictive (in term of hydrodynamic parameters and of geometry). It entails to consider a smooth air-gap even if the studied configuration corresponds to a grooved rotor. The case of grooved air-gaps was investigated experimentally by some authors [8-10]. The influence of the existence or not of the slots is only discussed in a qualitative way and some appreciations can be found. Unfortunately, no general relations adaptable to this study are obtained. Thus, the heat transfer coefficient is estimated using the correlation (4) corresponding to the smooth air-gap. In this correlation, an equivalent air-gap thickness is used to take into account the slots (rotor and stator).

$$
\begin{aligned}
N u_{\mathrm{a}} & =0.015\left(1+2.3 \frac{2 e_{\mathrm{eq}}}{L}\right) \eta^{0.45} \operatorname{Re}_{\mathrm{a}}^{0.8} \operatorname{Pr}^{0.33} \\
N u_{\mathrm{r}} & =0.046 T a^{0.66} \operatorname{Pr}^{0.33} \\
N u & =N u_{\mathrm{r}}+N u_{\mathrm{a}}
\end{aligned}
$$

where

$$
e_{\mathrm{eq}}=4 \frac{S_{\mathrm{m}}}{P_{\mathrm{m}}}=4 \frac{\pi\left(R_{\mathrm{s}}^{2}-R_{\mathrm{r}}^{2}\right)+108 p_{\mathrm{s}} l_{\mathrm{s}}-30 p_{\mathrm{r}} l_{\mathrm{r}}}{108\left(l_{\mathrm{s}}+l_{\mathrm{s}^{\prime}}+2 p_{\mathrm{s}}\right)+30\left(l_{\mathrm{r}}+l_{\mathrm{r}^{\prime}}+2 p_{\mathrm{r}}\right)}
$$

Using the geometrical and dynamic characteristics of the engine the value of the average heat transfer coefficient is obtained, and

$$
h=\frac{\lambda N u}{2 e_{\mathrm{eq}}}=22 \mathrm{~W} / \mathrm{m}^{2} \mathrm{~K}
$$

\subsubsection{Convective heat transfer between the water (external cooling agent) and the frame}

The frame represents the external envelope of the machine. It is in direct contact with the cooling surroundings water. In the case of an on-board motor, the water circulation is carried out using an external pump. It flows through a heat exchanger before flowing through the frame of the engine. In the case of a POD configuration, 


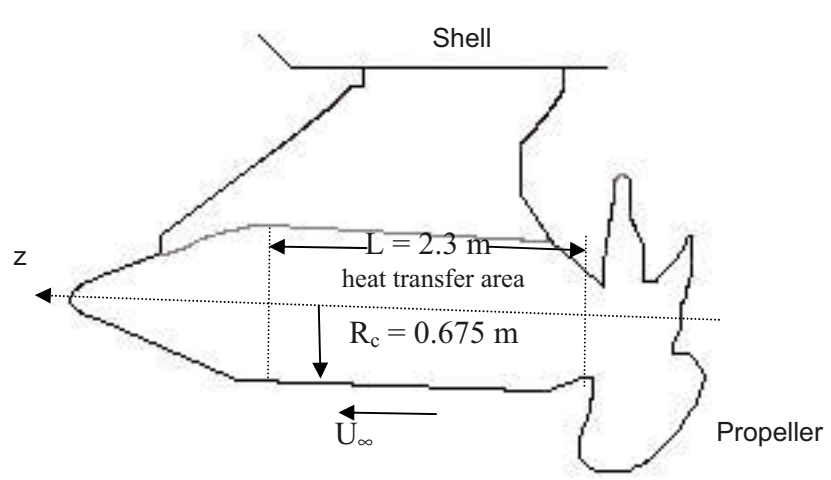

Fig. 5. POD version motor.

the engine is directly underwater and the frame is then in direct contact with sea water at the maximum relative speed of 20 knots, i.e. 10.3 m.s ${ }^{-1}$. The local convective heat transfer can then be evaluated using the Stasiulevichius correlation [11].

$$
\begin{aligned}
N u_{z}=0.0106 R e_{z}^{0.86} & {\left[1+0.37\left(\frac{z}{R_{\mathrm{c}}}\right)^{0.8} R e_{\mathrm{r}}^{-0.2}\right]^{0.14} } \\
& \times\left(\frac{T_{\mathrm{c}}}{T_{\infty}}\right)^{-0.25}
\end{aligned}
$$

with $R e_{z}=\frac{U_{\infty} z}{\nu}>2 \times 10^{6}$

The total averaged heat transfer for the whole zone is thus obtained by integration of this local Nusselt number over the length where the heat transfer occurred (see Fig. 5): $N u_{\mathrm{m}}=\frac{1}{L} \int_{0}^{L} N u_{z} \mathrm{~d} z$. Table 5 gathers the values of the heat transfer coefficients for both the configurations (on-board or POD).

\subsubsection{Convective heat transfer inside the rotor}

The airflow inside the rotor is due to the coupling of rotation from the rotor and the axial airflow caused by the blower. Few works about the identification of the convective heat exchanges in such a configuration can be found. Among them, some authors $[12,13]$ showed the rotation of the cylinder (rotor) causes a destabilizing effect on the laminar flow which becomes turbulent. Thus, the rate of heat transfer between the wall and the airflow becomes higher. Other authors [14-16] conclude the rotation of the cylinder reduces this heat transfer rate if the axial air inflow at the inlet is ever turbulent. It was however observed that these various studies cover a relatively limited range since they are valid only for high values of the geometrical ratio $L / D_{i}$. The few results available in the literature do not allow to accurately identify the trends or to obtain suitable correlations connecting the Nusselt number to both the axial and rotational Reynolds numbers. A model was developed to understand the heat transfer mechanisms in such a configuration. This study proposes a correlation at the high rotational speed and the low axial airflows, where the transfer only depends on the rotational Reynolds number [17].

$$
\begin{aligned}
N u & =2.85 \times 10^{-4} R e^{1.19} \\
R e & =\frac{\omega D_{i}^{2}}{2 \nu}>2.77 \times 10^{5}
\end{aligned}
$$

\section{End-regions study}

To accurately model the end-regions using a nodal approach, it is of paramount interest to know their aerodynamics. Aiming at that, CFD simulations of the internal flows of these end-regions were realized. These simulations were carried out using the commercial CFD software Fluent. The results obtained lets then identify parameters used in the nodal modeling.

\subsection{Geometrical description of the end-regions and grid}

The stator of the studied engine has 108 slots. However due to the periodicity, the symmetries of the problem, and the nature of the flows, an angular sector of $23.3^{\circ}$ was retained for this numerical study and allows a reduction in the cells number of the mesh and thus of the calculation cost. Figures 6 and 7 present respectively the simplified geometries for the two end-regions: the left end-region where the air inflows from the air-gap, and the right end-region where the air inflows from the rotor before outflow through the air-gap. On the real machine, the air flows into the rotor through 4 holes equally distributed on the rotor end-side (revolving wall). Then the air flows through the air-gap and is evacuated outside through 7 holes drilled in the frame. Due to the existence of these four holes in the rotor end-side, the exact modeling of the real machine requires to model at least a quarter of the machine. This option increases the number of cells in an excessive way. So, an equivalent annular surface is used instead of the real geometry (4 holes). The same approach was adopted for the 7 holes letting the air flows outside. The mass conservation lets determined in both cases the equivalent surfaces. Thus, in the simplified model for the right end-region, the air (at the temperature $T_{\infty}$ ) flows in by an annular space located the revolving part (rotor end-side) and flows out by an annular space (air-gap). The internal flow is supposed to be incompressible, turbulent, and three-dimensional. The physical properties of the fluid are assumed as constant.

The geometry and the grid were built using Gambit. This grid (quadrilateral and tetrahedral elements) has approximately 530000 cells in the right end-region and 900000 in the left one. These significant cell numbers are due to the alternation between big size and small size volumes (space between end-windings, air-gap,...). Figures 8 and 9 present the grid of these two end-regions.

The thermal and aerodynamic boundary conditions of the problem are gathered into Tables 6 and 7 for both 
Table 5. Heat transfer coefficients between the frame and the cooling water.

\begin{tabular}{cccc}
\hline \multirow{2}{*}{ Configuration } & water speed $\left({\left.\mathrm{m} . \mathrm{s}^{-1}\right)}^{2} R e_{l}=\frac{1}{L} \int_{0}^{L} \frac{z U_{\infty}}{\nu} \mathrm{d} z\right.$ & $h_{\mathrm{m}}=\frac{\lambda N u_{\mathrm{m}}}{L}$ \\
\hline on board motor & 2 & $10^{7}$ & $2757 \mathrm{~W} \cdot \mathrm{m}^{-2} \cdot \mathrm{K}^{-1}$ \\
POD version & 10.3 & $3.5 \times 10^{7}$ & $11575 \quad \mathrm{~W} \cdot \mathrm{m}^{-2} \cdot \mathrm{K}^{-1}$ \\
\hline
\end{tabular}

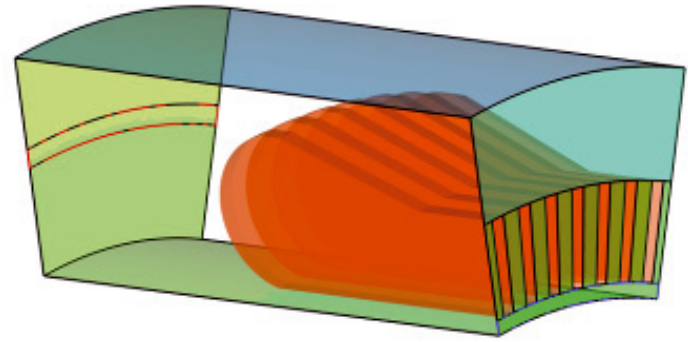

Fig. 6. Geometry of the left end-region.

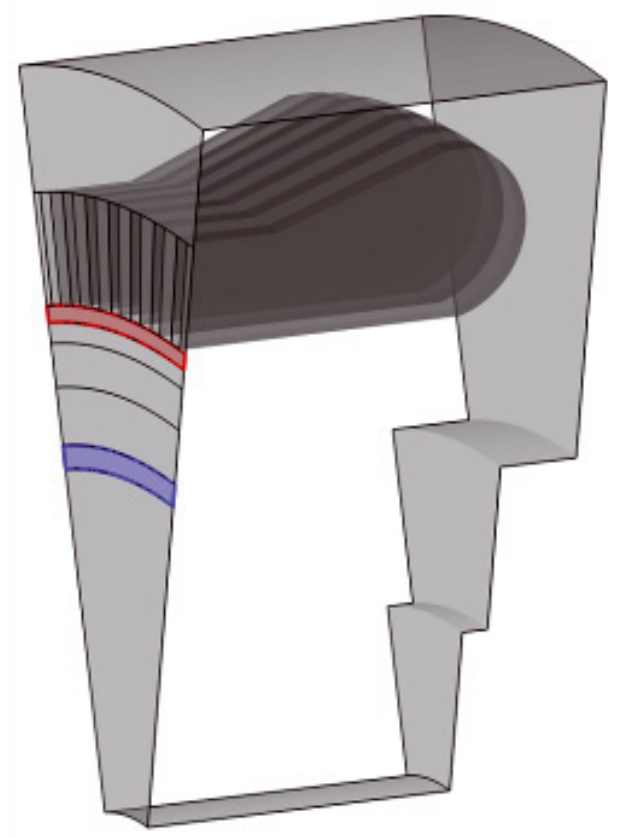

Fig. 7. Geometry of the right end-region.

the end-regions. These temperatures are estimated using a nodal modeling. Simulations were carried out for only one operation point characterized by an inlet mass flow rate of $0.18 \mathrm{~kg} . \mathrm{s}^{-1}$ and a rotational speed of $250 \mathrm{rpm}$. This imposes the inlet air velocity in the end-regions and the rotational speed of the revolving walls. The direction of the inlet velocity vector is imposed using the components of the velocity vector (high tangential component).

\subsection{Numerical model}

Fluent is based on the finite volumes method to express the mass, the momentum, as well as the energy

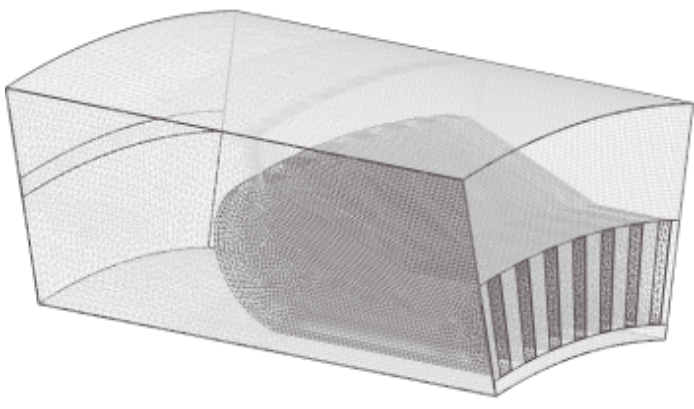

Fig. 8. Mesh of the left end-region.

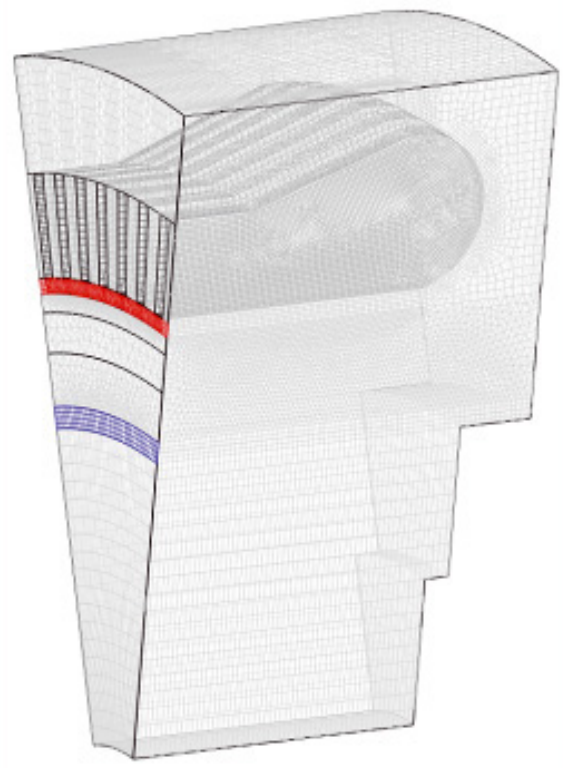

Fig. 9. Mesh of the right end-region.

conservation (Navier-Stokes equations). The turbulent phenomena are taken into account using the well-known $k-\varepsilon$ RNG model. This statistical model uses two transport equations (closure equations) for the turbulent kinetic energy $(k)$ and for the dissipation rate $(\varepsilon)$. This model, in its RNG formulation (based on the theory of the renormalization group), was chosen because it has an option well adapted to the types of studied flows ("swirl dominated flows") and was suitable for many configurations. For this numerical model, the wall laws were also used $\left(y^{+} \approx 30\right)$. The discretization scheme chosen for the pressure is the "PRESTO!" model. This model is recommended [18] in the case of rotating flows. The first order "Upwind" scheme was used for the equations of 
Table 6. Boundary conditions of the right end region.

\begin{tabular}{ccc}
\hline Part & Thermal & Motion \\
\hline Rotor end-side & $45^{\circ} \mathrm{C}$ & Rotation, 250 rpm \\
Rim & $129{ }^{\circ} \mathrm{C}$ & Rotation, 250 rpm \\
Magnets & $130{ }^{\circ} \mathrm{C}$ & Rotation, $250 \mathrm{rpm}$ \\
Magnetic tooth & $97{ }^{\circ} \mathrm{C}$ & Static \\
End windings & $174{ }^{\circ} \mathrm{C}$ & Static \\
Magnetic sheets & $66{ }^{\circ} \mathrm{C}$ & Static \\
Frame & $40{ }^{\circ} \mathrm{C}$ & Static \\
Bearings & Adiabatic & Static \\
Shaft & Adiabatic & Rotation, 250 rpm \\
Air inlet & $45{ }^{\circ} \mathrm{C}\left(=T_{\infty}\right)$ & $Q_{\mathrm{m}}=0.18$ kg.s \\
\hline
\end{tabular}

Table 7. Boundary conditions of the left end region.

\begin{tabular}{ccc}
\hline Part & Thermal & Motion \\
\hline Magnetic tooth & $93{ }^{\circ} \mathrm{C}$ & Static \\
End windings & $146{ }^{\circ} \mathrm{C}$ & Static \\
Magnetic sheets & $64{ }^{\circ} \mathrm{C}$ & Static \\
Frame & $40{ }^{\circ} \mathrm{C}$ & Static \\
Bearings & Adiabatic & Static \\
Air inlet & $90{ }^{\circ} \mathrm{C}\left(=T_{\infty}\right)$ & $Q_{\mathrm{m}}=0.18 \mathrm{~kg} \cdot \mathrm{s}^{-1}$ imposed direction \\
\hline
\end{tabular}

moment, energy and transport (turbulent kinetic energy and rate dissipation). For the pressure-velocity coupling, the SIMPLE model was retained for its wide range of use. The convergence criteria are based on the values of the residues. The solution is supposed to be converged when all the residues are lower than $10^{-7}$. This convergence was also checked by verifying the energy and mass balances.

\subsection{CFD results}

Figure 10 shows the velocity vectors field in the right end-region letting obtain internal aerodynamics in particular around the end-windings. This figure shows the main part of the inlet airflow directly flows into the airgap. Maximum velocity magnitudes are located on the area between the rotor inlet and the outlet through the air-gap (speed ranging from 6 to $11 \mathrm{~m} . \mathrm{s}^{-1}$ ). Velocities in the other areas are definitely lower (between 0 and $\left.1.5 \mathrm{~m} . \mathrm{s}^{-1}\right)$. The importance of the tangential component clearly appears in Figure 11 which represents the velocity field (in a radial plan). A swirling effect of the flow can be observed there. It is caused by both the rotation and the driving effect of the various layers of air (viscous effects).

Figures 12 and 13 present respectively the velocity field in an axial plane crossing an end-winding and in an axial plane between two end-windings. These figures confirm what appeared in Figure 10, namely that the majority of the inlet airflow flows immediately into the air-gap and a negligible part flows around the end-windings.

Contra-rotating recirculation areas where the velocity magnitude is low can also be identified. One is located below the end-windings, where the velocities remain very low. It is mainly caused by the particles flowing slowly

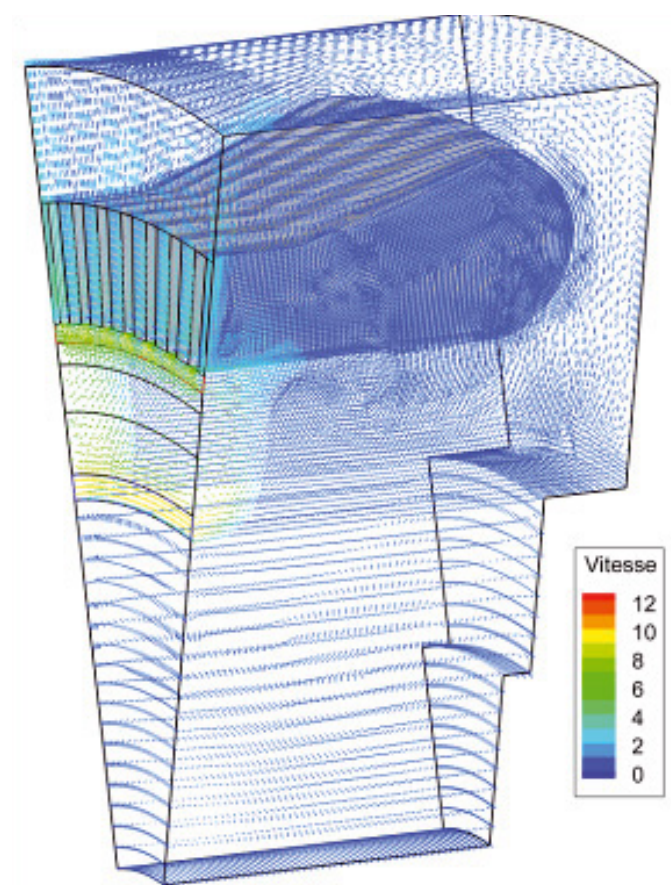

Fig. 10. Velocity vector field in the right end-region.

downward from the upper part. These lasts are slowed down due to the presence of the main airflow flowing out of this end-region through the air-gap. These figures also point out the presence of two contra-rotating recirculation areas in the lower part of this end-region. These two low 


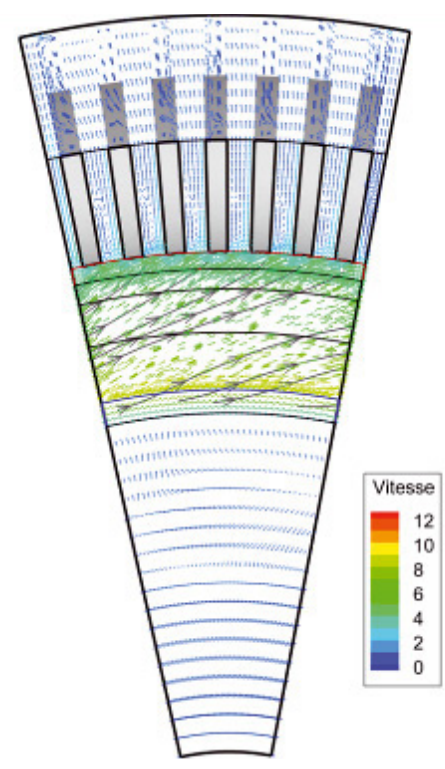

Fig. 11. Velocity field in a radial cross section of the right end-region.

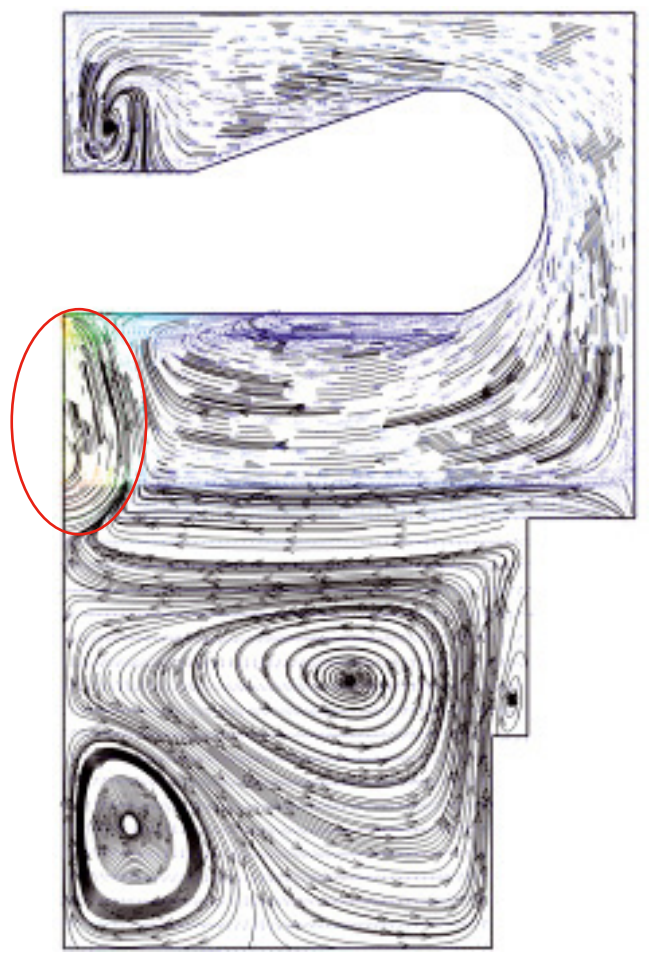

Fig. 12. Velocity field in an axial cross section of the right end-region (through an end-winding).

intensity recirculation areas occur in the whole lower part of the right end-region.

Figure 14 shows the velocity vector field in the left end-region. The most part of the inlet airflow flows directly outside the machine without crossing through the end-windings. Due to the important tangential velocity component, an important swirling effect of the air can be noted. This figure also shows that the maximum velocity

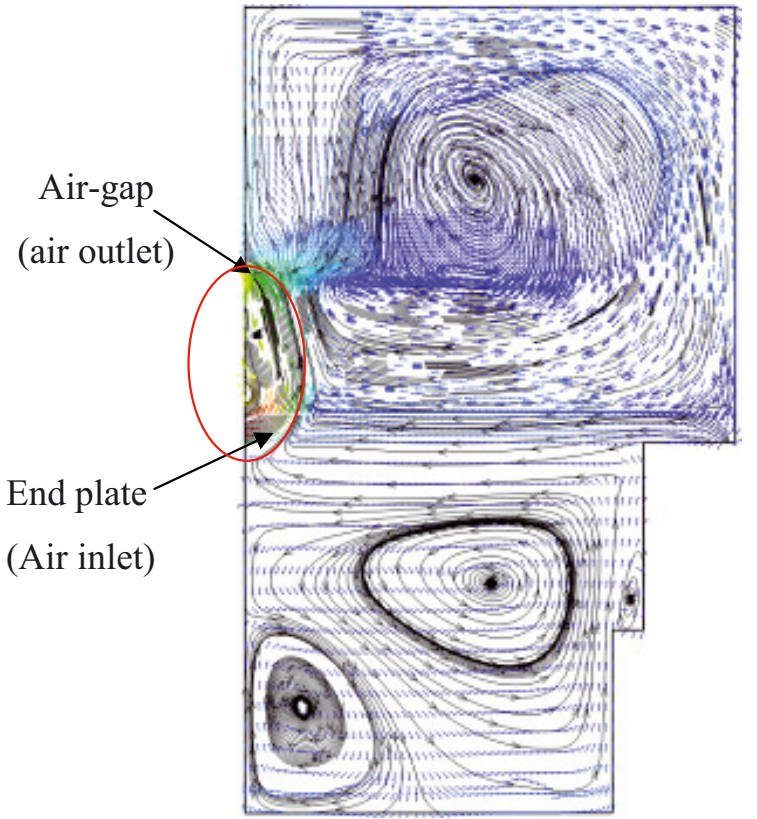

Fig. 13. Velocity field in an axial cross section of the right end-region (between two end-windings).

magnitude zones are under the end-windings and at the outlet, whereas the minimal velocity magnitude areas are located between the end-windings and in the upper part of the left end-region (above the end-windings).

Figures 15 and 16 present the velocity vectors field and the path lines in axial plane of the left end-region. The previous observations can be found again, namely that the majority of the airflow penetrating into the left end-region flows directly outside without crossing the end-windings. In particular, a very small part of the main flow tends to flow upwards to the frame and reached the top of the left end-region. This part flows along the top of the frame before flowing downwards along the vertical wall of the end-region. Thus, a recirculation area can be observed. This last, of low magnitude, occurs in the whole upper part of the end-region. Finally, the flow is composed of three zones, the main flow which flows directly outside, and two contra-rotating recirculation areas.

The CFD results show the quasi-totality of the inlet airflow flows directly outside without crossing through the end-windings what is harmful for cooling. Convective heat exchanges between the walls of this area and the inner air can thus be legitimately assumed as controlled by the free convection.

To simplify the nodal model, the end-windings are modeled by two parallel parts, as shown in Figures 17 and 18. In the upper part of the end-regions, three kinds of convective heat transfer coefficient can be identified. They are gathered in Table 8 . The characteristic length used to identify the convective heat transfer coefficient $h=\frac{\lambda N u}{\ell}$ is the element length.

The rotor end-side is considered in this work as a rotating disc placed at a distance $d$ of a static wall. According to Kreith's results [21], for the values $d / R$ greater than 

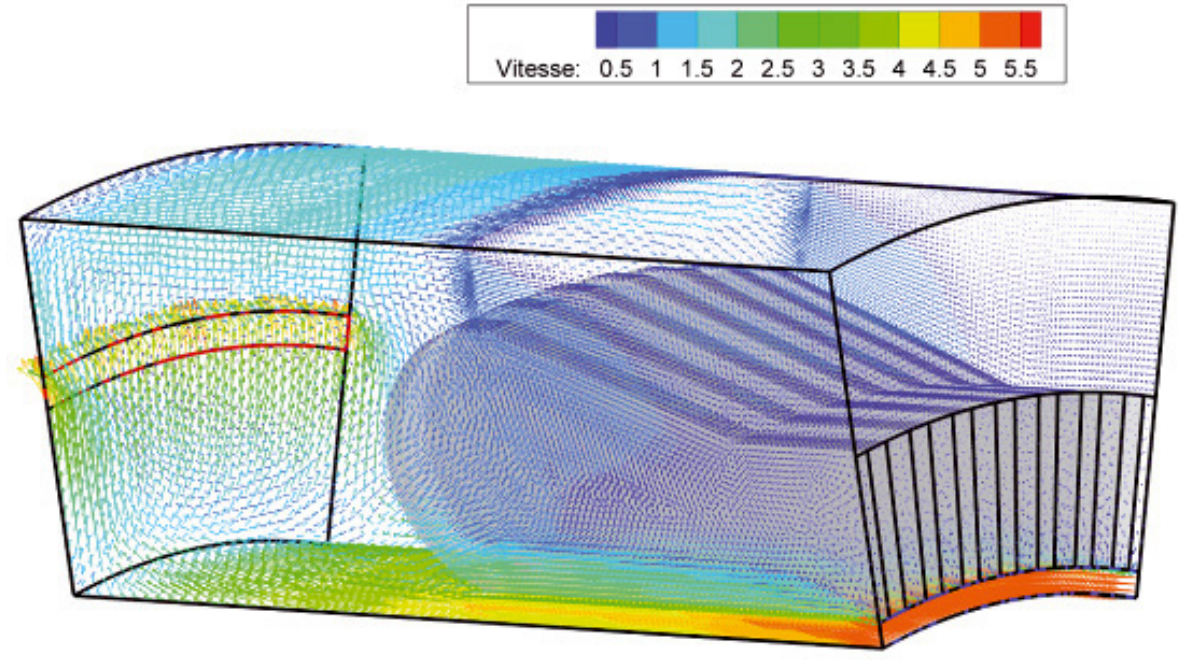

Fig. 14. 3D velocity field in the left end-region.

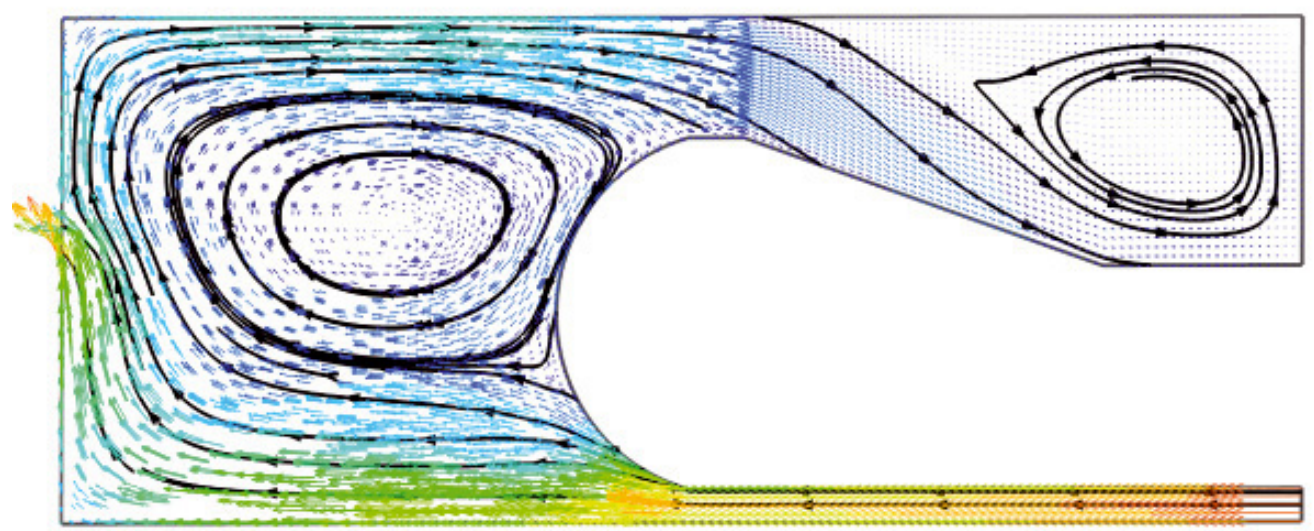

Fig. 15. Velocity field in an axial cross section of the left end-region (through an end-winding).
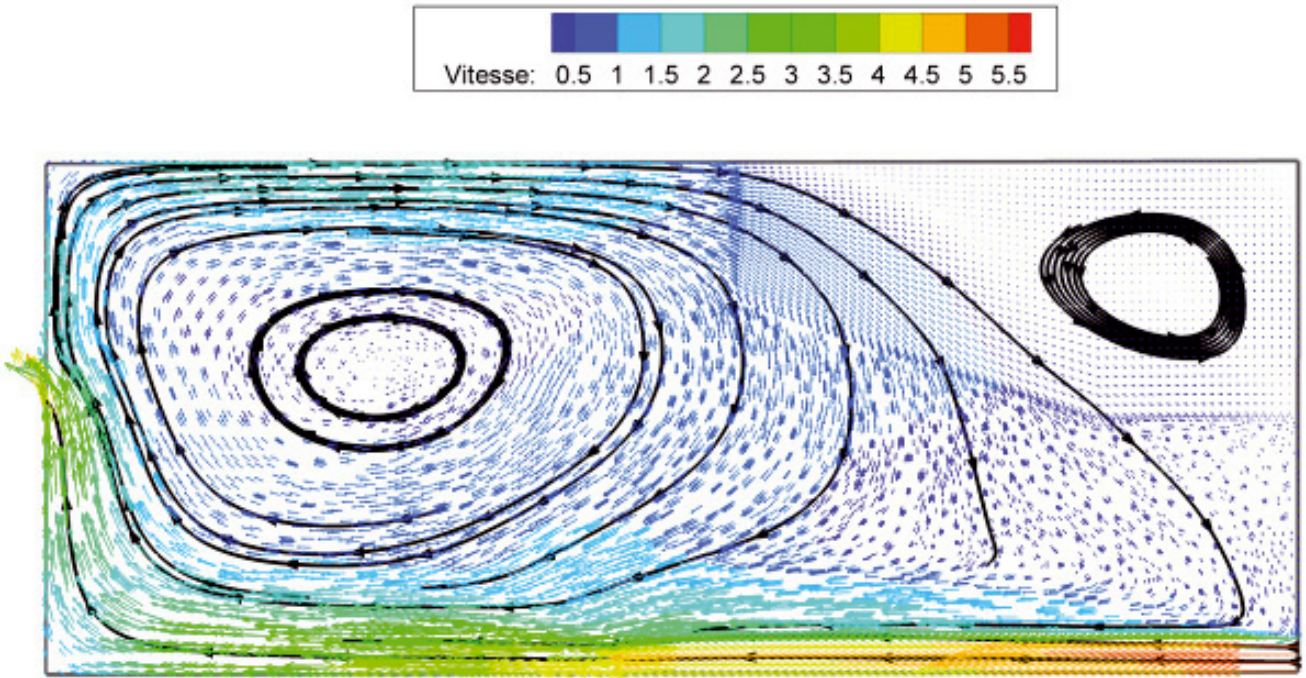

Fig. 16. Velocity field in an axial cross section of the left end-region (between two end-windings). 
Table 8. Correlations used.

\begin{tabular}{cccc}
\hline Free convection & vertical flat plate & $\begin{array}{c}\text { horizontal plate } \\
\text { heated from below }\end{array}$ & $\begin{array}{c}\text { horizontal flat plate } \\
\text { heated from above }\end{array}$ \\
\hline Authors & Mc Adams [19] & Mc Adams [19] & Fishenden and Saunders [20] \\
Correlation & $N u=0.59 R a^{0.25}$ & $N u=0.27 R a^{0.25}$ & $N u=0.54 R a^{0.25}$ \\
Validity & $10^{4}<R a<10^{9}$ & $3 \times 10^{5}<R a<3 \times 10^{10}$ & $10^{5}<R a<10^{7}$ \\
\hline
\end{tabular}

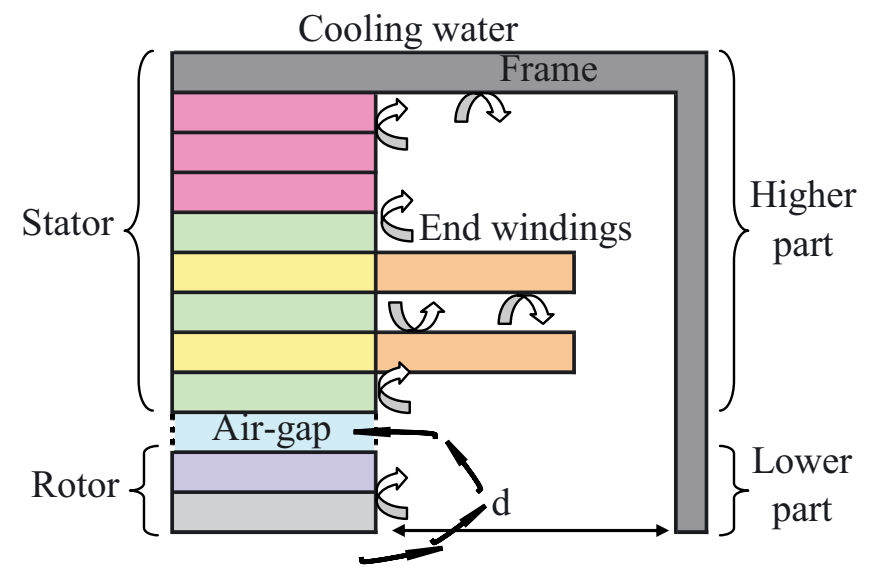

Fig. 17. Convective heat transfer in the right end-region.

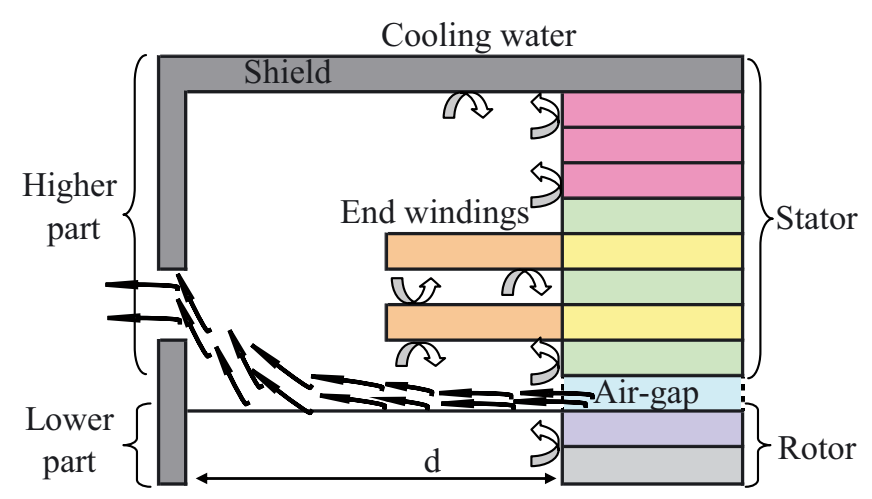

Fig. 18. Convective heat transfer in the left end-region.

0.2 , the interaction between the rotating and the static part is very low and the Nusselt number is the same as the one obtained at the surface of a single rotating disc in still air. In our case, the ratio $d / R$ is close to 0.5 and the Reynolds number is about $10^{5}$ for a rotating speed of $250 \mathrm{rpm}$. According to Popiel and Boguslawski [22], this condition corresponds to a transition regime from laminar to turbulent and the convective heat transfer coefficient is obtained using the following correlation

$$
N u=0.0188 R e^{0.8}, \quad \text { where } \quad R e=\frac{\omega R}{\nu}
$$

Thus, the convective heat transfer coefficient obtained in this case is about $24 \mathrm{~W} . \mathrm{m}^{-2} \mathrm{~K}^{-1}$.

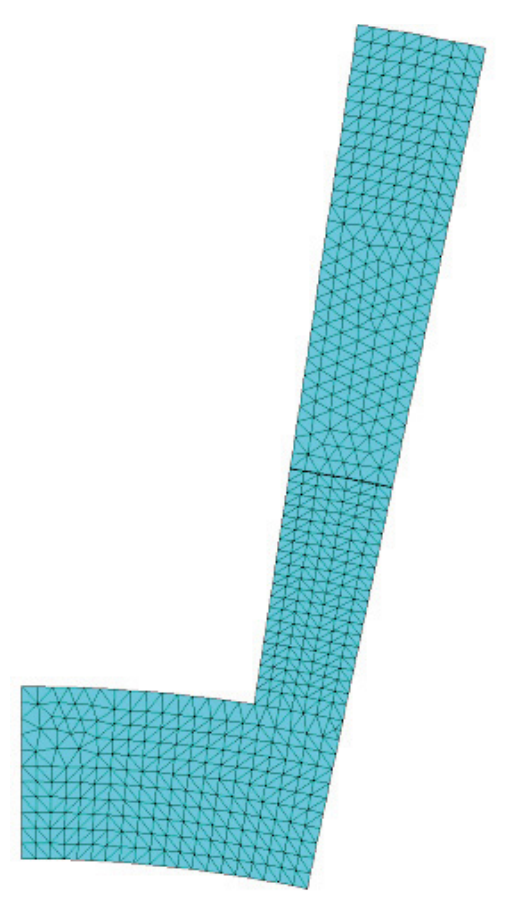

Fig. 19. Finite-element mesh.

\section{Validation of the model and results}

\subsection{Nodal network}

The validation is carried out on a $2 \mathrm{D}$ model made of basic elements taking into account the geometry of each part (number of poles, slots, teeth...) as shown in Figures 3, 4. In the nodal model, the (thermal) network must take care of three criteria: heterogeneity of materials, heat (or sink) sources and isotherm areas. The first two criteria are easy to respect on the contrary to the last one. Ansys (the finite-elements computer code) was used to identify isotherm areas (third criterion). The convergence of Ansys was obtained with a grid containing 1925 nodes and shown in Figure 19. The nodal network was built by gathering in the same area all the consecutive elements where the temperature is the same at about $2{ }^{\circ} \mathrm{C}$. This nodal network plots in Figure 20 has 1 node for the magnets, the air-gap and the frame, 2 nodes for the rim, 9 nodes for the slot and the tooth and 3 nodes for the magnetic sheet. In such conditions, only the slot and the tooth need to be refined to respect the temperature inhomogeneity inside these parts. The complete 2D thermal network has 26 nodes. Figure 21 compares the results obtained for the temperature using both models 


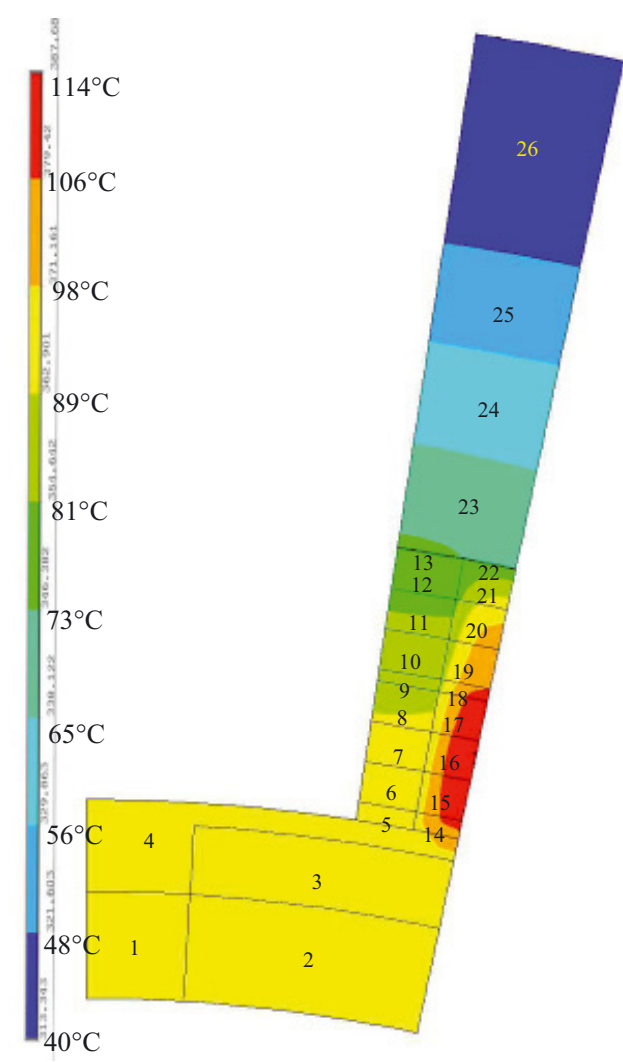

Fig. 20. Thermal cartography (Ansys) and nodal model mesh.

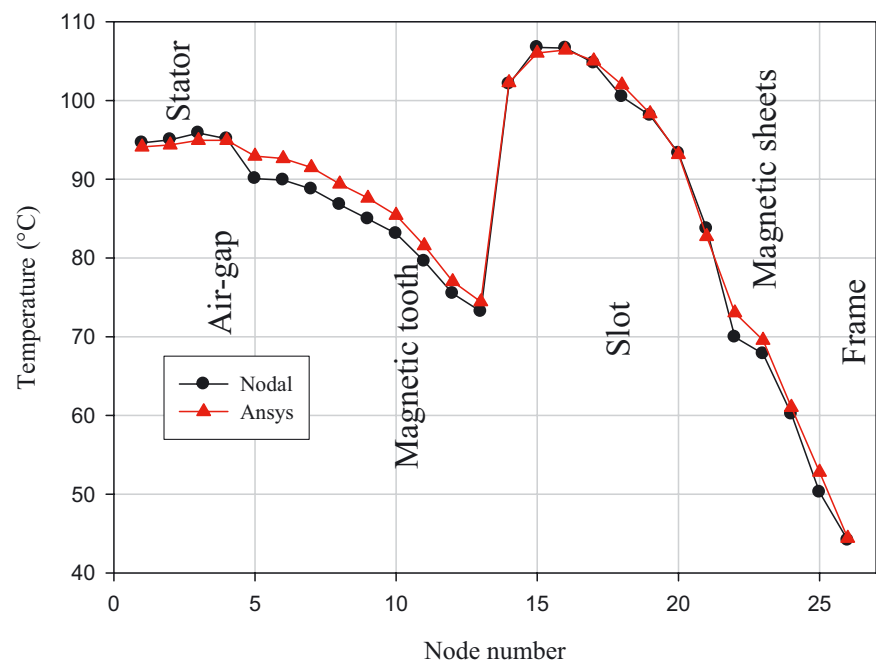

Fig. 21. Comparison of the temperatures obtained using both methods (nodal and finite-elements).

(nodal or Ansys). The plots have the same trends and no significant differences can be noticed pointing out the suitability of the developed model.

\subsection{Results and discussion}

The results presented thereafter correspond to a $3 \mathrm{D}$ model of the complete synchronous electrical engine. This
3D model takes into account the end-windings. In the longitudinal direction, 8 calculus sections - $(r, \theta)$ planeover the entire length of the machine $(2.3 \mathrm{~m})$ were used. A greater number of sections was tested and does not change significantly the temperature field into the whole machine. In order to well model the end-regions of the engine, the end-windings were axially divided into three sections. Thus, a 378 thermal nodes network (14 sections $\times 27$ nodes per section) was used. It can be noticed that by considering the whole machine (symmetries...), a 36456 calculation nodes network has to be considered, which need more CPU time but remains reasonable to model the complete machine.

The temperature field of the machine resulting from modeling is shown in Figure 22.

Using this thermal cartography, Figure 23 plots the temperature variations of the magnet, of the air-gap and of the copper. The maximum values of temperature which must not be exceeded in order to guarantee the correct engine operation are for the magnets $T$-magnet $<90{ }^{\circ} \mathrm{C}$ and for the cooper $T$-copper $<130{ }^{\circ} \mathrm{C}$. With these considerations, the hottest parts of the machine are located close to the end-windings and the magnets. The airflow rate imposed into the machine is very low and does not allow a correct cooling of the end-windings. It is to note that the air temperature into the rotor increases along the axis since a part of the energy released by the rotor is transferred to the inner airflow (into the empty rotor). The same trend for the temperature of the magnets can be observed. It can be explained by the warm up of the inner air temperature into the rotor. Indeed, due to this inner air warm up, the cooling efficiency decreases and then the magnets are less cooled down at the outlet of the rotor. The temperatures observed on the frame are about $44{ }^{\circ} \mathrm{C}$. This is due to the proximity of water at $40{ }^{\circ} \mathrm{C}$ (most unfavorable case) and the high convective heat transfer coefficient between the water and the frame. In contrast with that, the rotor temperatures are far from the inflow temperature $45{ }^{\circ} \mathrm{C}$. This is due to the losses in the magnets, which heat up the air in the rotor and the low value of the airflow rate. Concerning the winding, the copper temperature remains almost constant except in the end-windings.

Globally, the temperatures found are harmful for the correct operation of the engine, resulting in reconsidering its cooling principle. Aiming at that, a sensibility study of the temperatures of the hottest zones is necessary to determine the parameters which influence the cooling of the machine.

\subsection{Study of the sensibility}

An analysis of the sensibility is carried out in order to identify the parameters which influence the cooling of the machine. This analysis allows studying the temperature variation of the hot zones namely the magnets and the end-windings versus various parameters such as the airflow rate and the heat transfer coefficients in the rotor, in the air-gap and in the frame. For these parametric studies, 


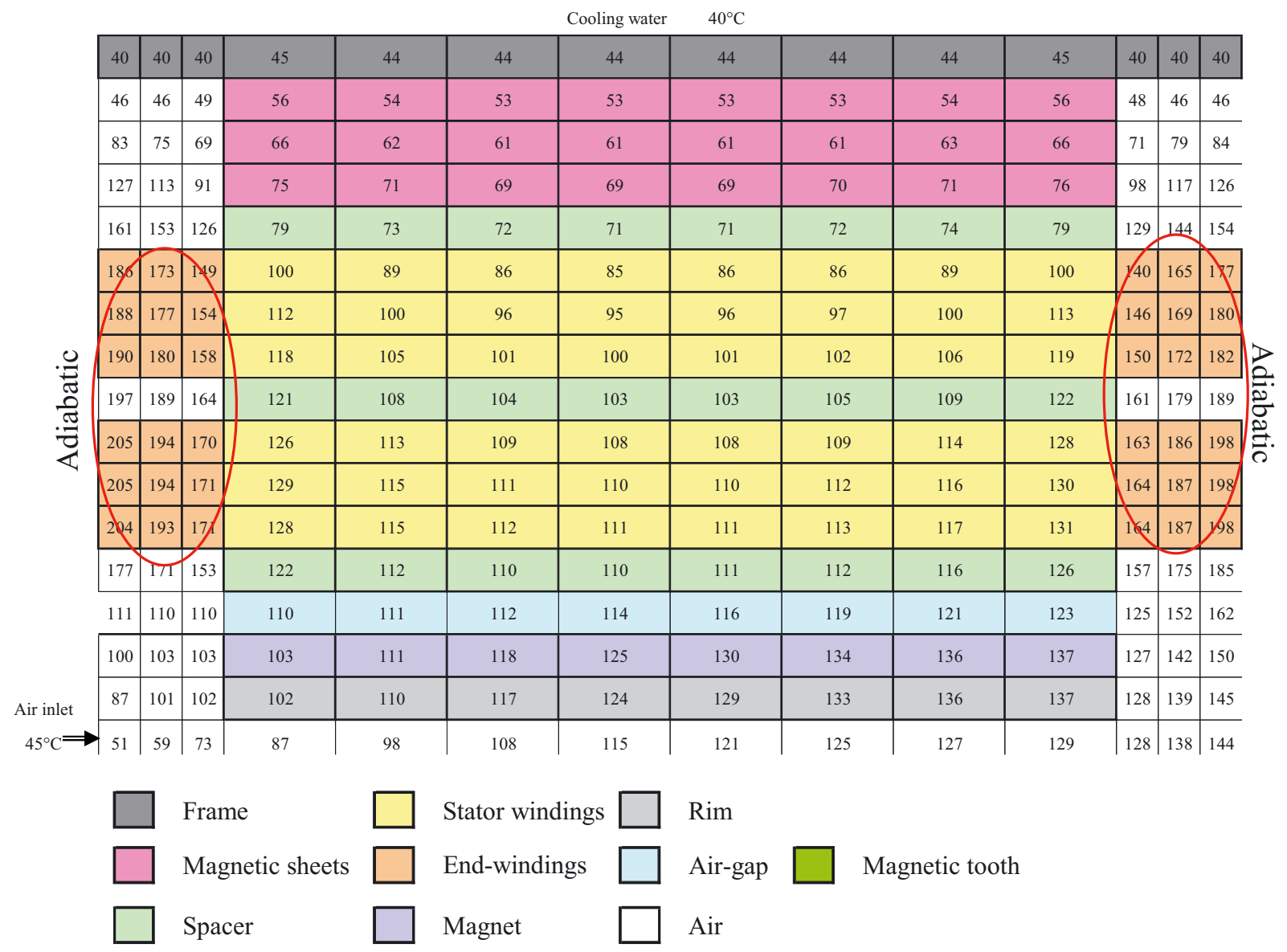

Fig. 22. Temperature field $\left({ }^{\circ} \mathrm{C}\right)$.

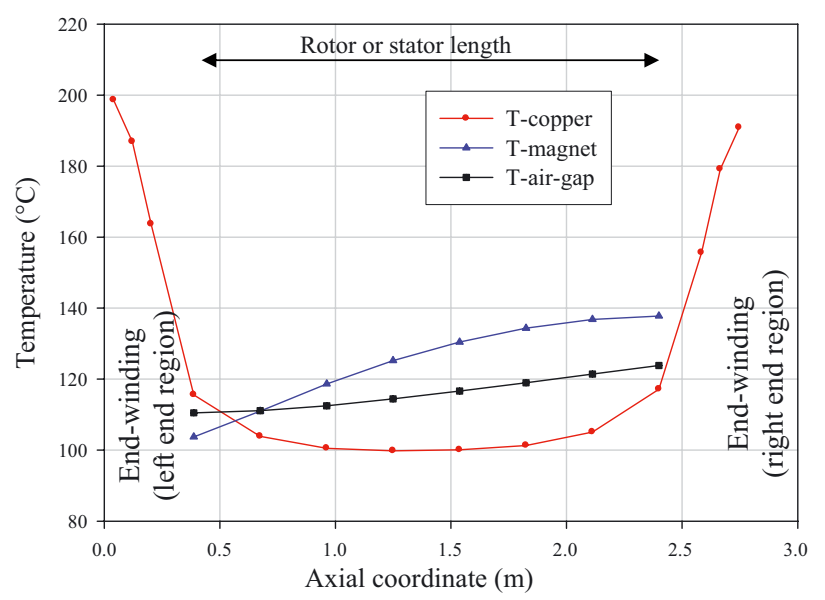

Fig. 23. Temperature evolution versus the axial coordinate.

only one quantity varies whereas the others are assumed as constant and considered at their reference value. These different quantities vary in a range where they have a physical meaning.

The airflow rate plays an important role in the estimation of the convective heat transfer between a solid

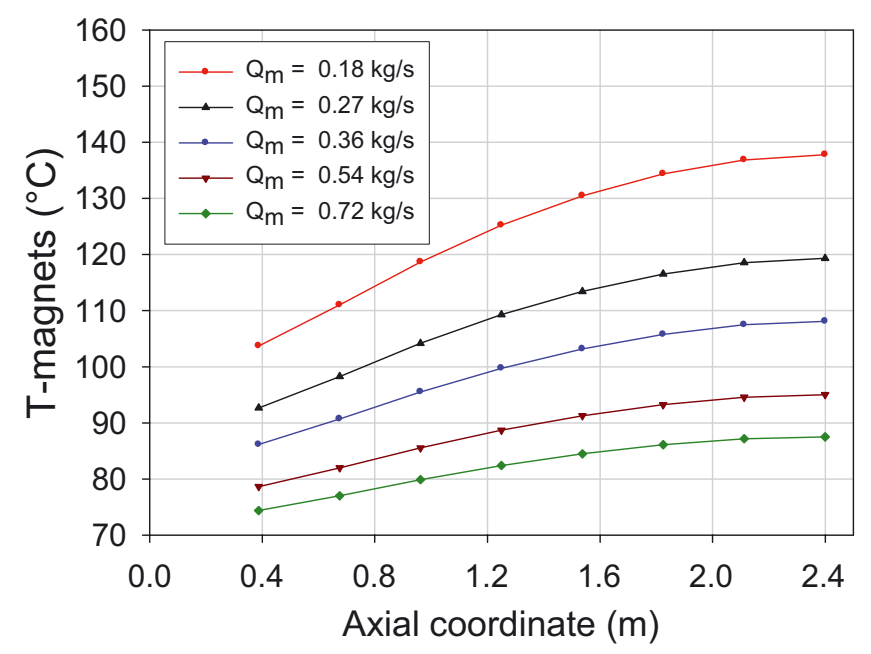

Fig. 24. Airflow influence on the axial evolution of the magnet temperature.

node and a fluid one, but also in the heat balance of the two consecutive air nodes. Figure 24 illustrates the effects of the air flow rate on the magnets temperature. All the plots have similar trends. The temperature increases with the axial coordinate. The areas of high sensibility are in the regions far from the rotor inlet. The 


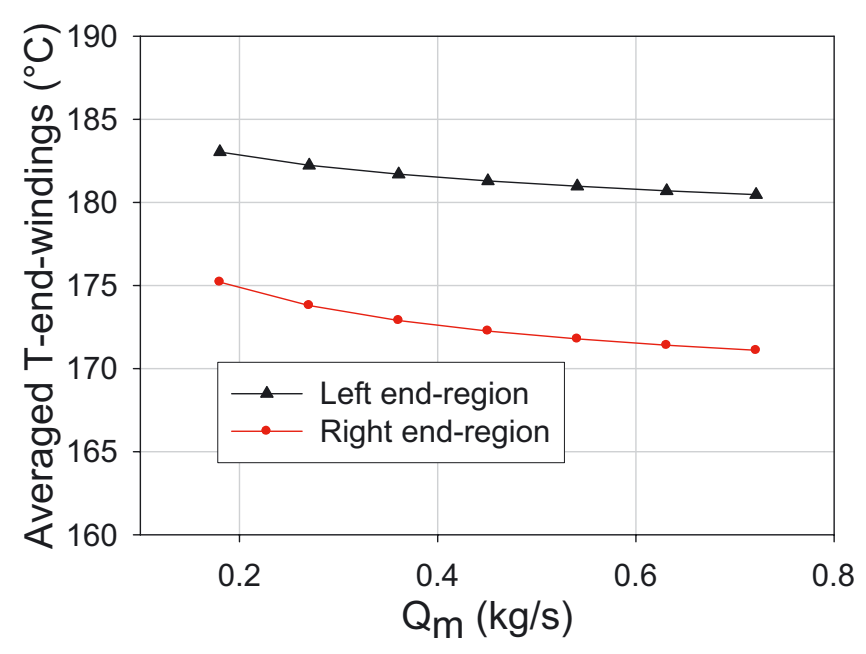

Fig. 25. Airflow influence on the end-winding temperature.

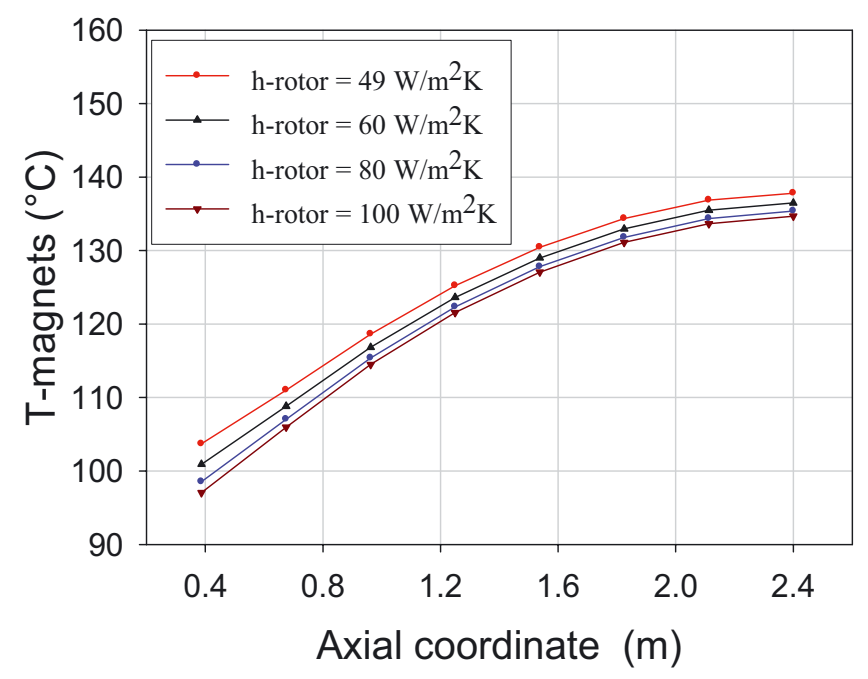

Fig. 26. Evolution of the magnet temperature with $h$-rotor.

magnet temperature decreases when the airflow rate augments. For instance, an augmentation of the airflow rate from 0.18 to $0.72 \mathrm{~kg} . \mathrm{s}^{-1}$ entails a magnet temperature reduction ranging between 30 (inlet) and $50{ }^{\circ} \mathrm{C}$ (outlet). Globally, the magnets temperature is very sensitive to the airflow rate variation. To ensure a correct cooling of the magnets, an airflow rate equals to $0.72 \mathrm{~kg} . \mathrm{s}^{-1}$ would be more appropriate. Figure 25 presents the evolution of the end-windings temperature for both side of the machine as a function of the airflow rate. These temperatures are weakly sensitive to the airflow variation. It can be explained using the air velocity vectors field which shows the end-windings are not crossed by the airflow. Then the transfer in the upper regions of the end-regions is only controlled by free convection. For instance, an augmentation of the airflow rate from 0.18 to $0.72 \mathrm{~kg} . \mathrm{s}^{-1}$ entails a temperature drop equals to about $4{ }^{\circ} \mathrm{C}$.

Figure 26 presents the axial evolution of the magnet temperature versus the convective heat transfer coefficient into the rotor: $h$-rotor. Whatever the values of this coefficient, the magnet temperature increases when the

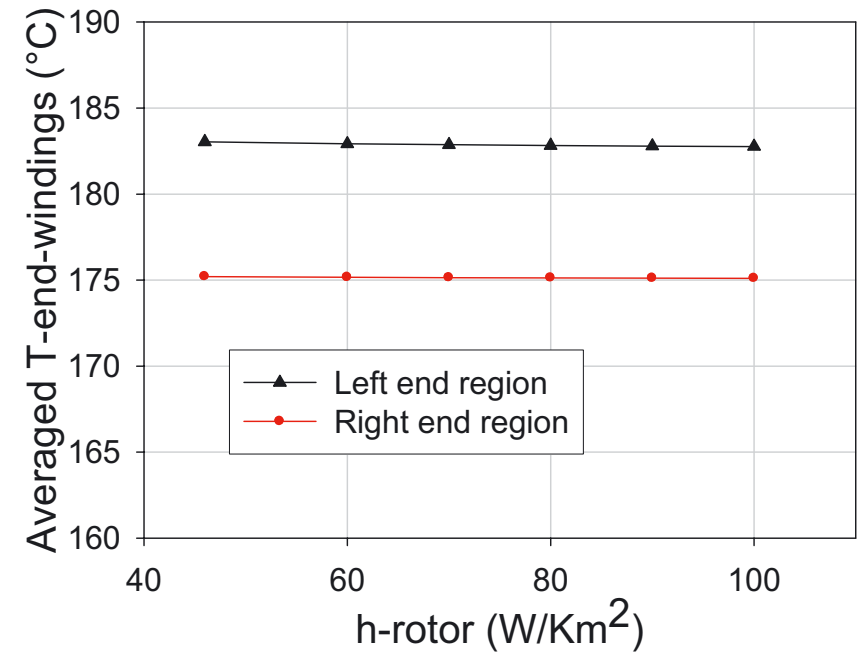

Fig. 27. Evolution of the end-winding temperature with $h$-rotor.

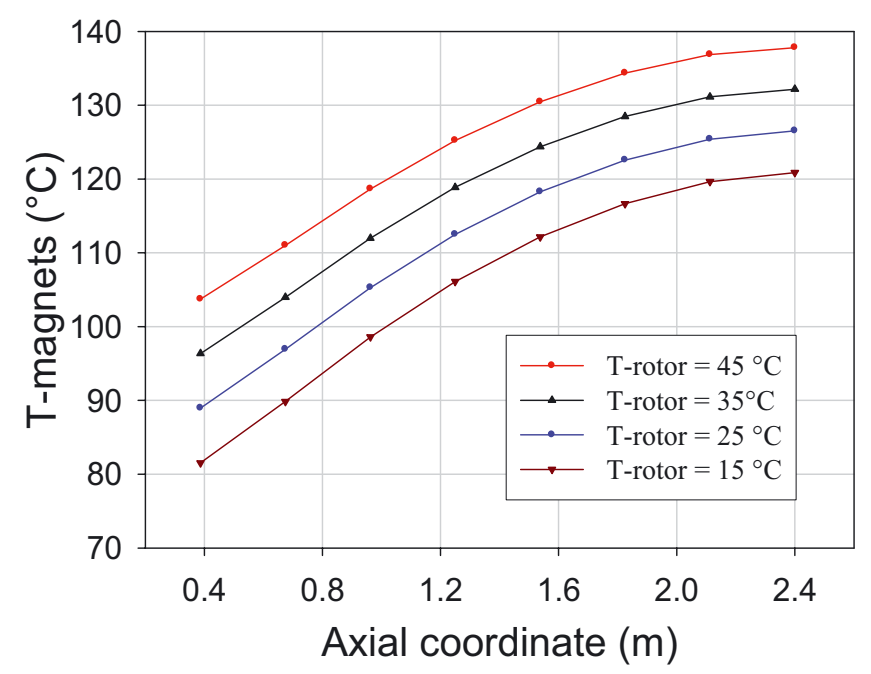

Fig. 28. Evolution of the magnet temperature with $T$-rotor.

air flows inside the rotor. These values are lower when $h$-rotor increases. This decrease remains all the same limited due to the significant temperature of the air in the rotor. In such a situation, the increase of $h$-rotor is not high enough to lower the magnet temperature in a suitable way. The same conclusions can be drawn for the end-windings temperatures which are weakly sensitive to the $h$-rotor variation, as shown in Figure 27. The important increase in the heat transfer coefficient (from 45 to $100 \mathrm{~W} \cdot \mathrm{m}^{-2} \cdot \mathrm{K}^{-1}$ ) only reduces to about $1{ }^{\circ} \mathrm{C}$ the endwindings averaged temperature.

Figure 28 represents the axial evolution of the magnet temperature with the inlet temperature of air: $T$-air_inlet. For the values considered, similar trends can be noted, but the magnet temperature is quite different. The lower the air inlet temperature is, the lower is the magnet temperature. Even if a certain improvement can be noted, the reduction in the inlet temperature of air cannot ensure a suitable cooling of the magnets since they have 


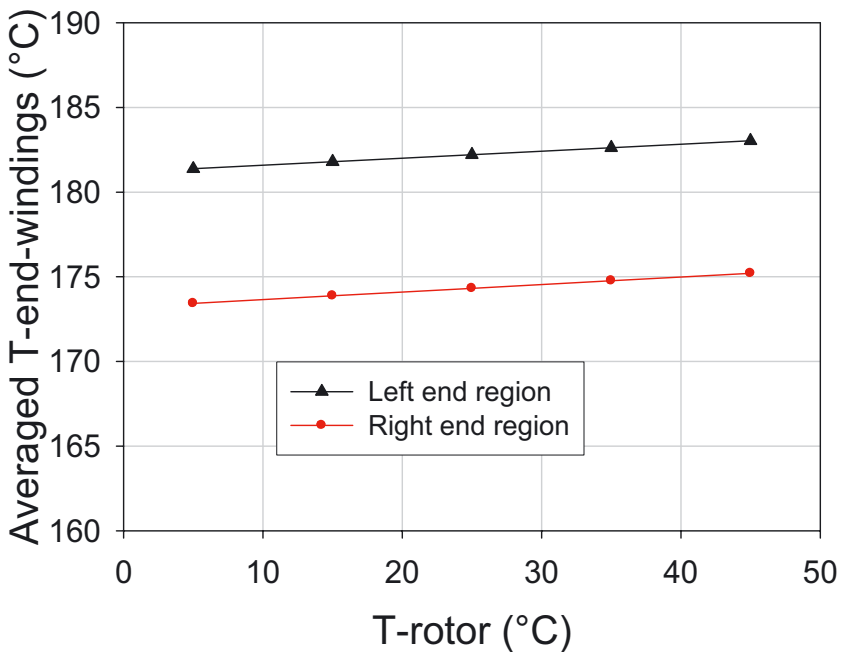

Fig. 29. Evolution of the end-winding temperature with $T$-rotor

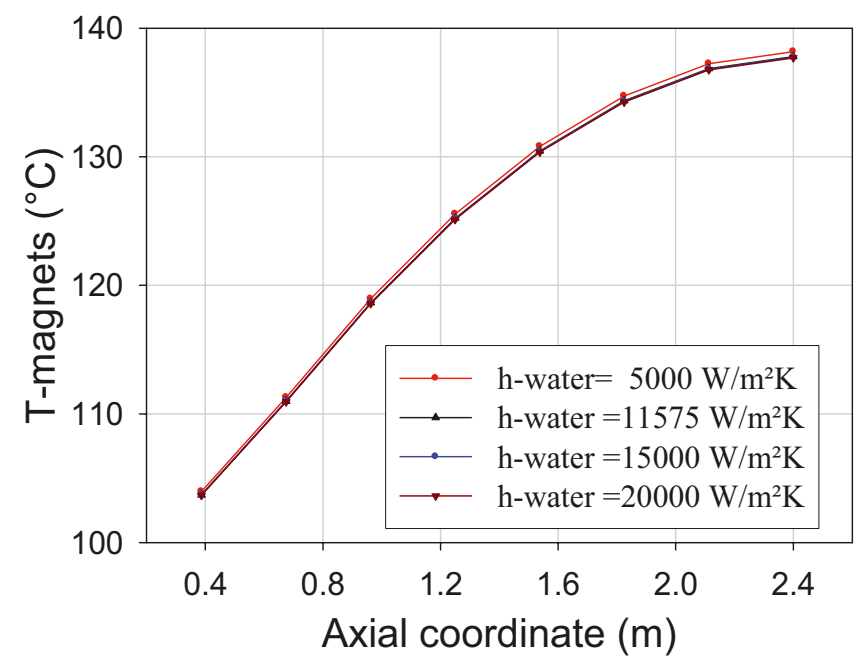

Fig. 30. Evolution of the magnet temperature with $h$-water.

not to exceed $90{ }^{\circ} \mathrm{C}$. The evolution of the end-windings temperature with $T$-air_inlet is plotted in Figure 29. The inlet temperature of air has a very weak influence on the end-winding temperature since this parameter induces a temperature drop which does not exceed $2{ }^{\circ} \mathrm{C}$.

The variation of the heat transfer coefficient is caused by the speed variation of ship in the case of the POD version and the speed of cooling water in the case of an on-board motor. The influence of $h$-water on the magnet temperature is plotted in Figure 30. It clearly appears that the magnet temperature is not dependent to this coefficient variation since the plots of the temperature evolution along the axis are almost identical. In Figure 31, it is also found that the end-winding temperature is not dependent of $h$-water. Indeed, the temperature remains close to $183^{\circ} \mathrm{C}$ for the end-windings in the left end-region and of $175^{\circ} \mathrm{C}$ for the other one. For both cases, the temperature reduction does not exceed $2{ }^{\circ} \mathrm{C}$. This previous analysis lets identify the parameters which influence the

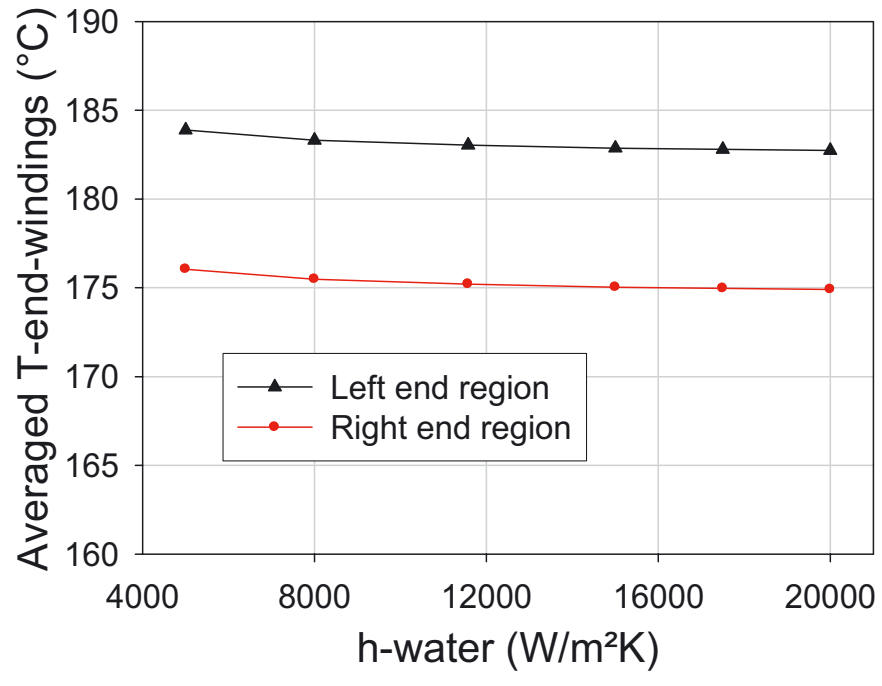

Fig. 31. Evolution of the end-winding temperature with $h$-water.

thermal behavior of the machine. From this study, it can be concluded that only the airflow rate plays an important role on the cooling of the magnets whereas the endwindings are not dependent to this airflow.

\section{Cooling techniques or solutions}

This part aims to analyze the efficiency of several solutions to enhance the cooling. To decrease the magnet temperature, it would be suitable to improve the heat transfer between the rotor and the air. Aiming at that, three solutions are studied. The first one implies to increase the airflow rate. This solution requires the installation of more powerful and/or more efficient fans. This solution is not acceptable for economic considerations as well as noise, weight and cumbersome issues. The second solution consists in increasing the convective conductance $(h S)$ using a slight airflow rate augmentation and the use of fins into the rotor. The third and last solution consists in introduce inside the rotor a pipe in which flows cooling water. This pipe plays the role of a heat exchanger between the internal air of the rotor and the cooling agent (water). Concerning the end-windings, none of the tested solutions improves the cooling. Another solution consists in install a thermal bridge between the end-windings and the frame, letting dissipate a part of the end-winding energy to the external water (through the thermal bridge and then through the frame).

\subsection{Rotor with longitudinal fins}

The heat exchange from the rotor to the inner air can be enhanced by increasing the rim surface using fins [23]. This solution is presented in Figure 32. In the proposed configuration, the rotor has longitudinal fins. These fins 


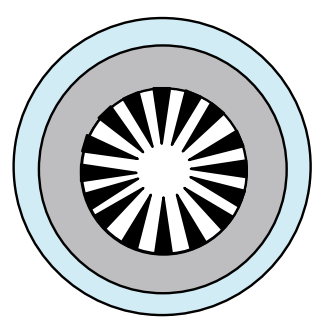

Radial view

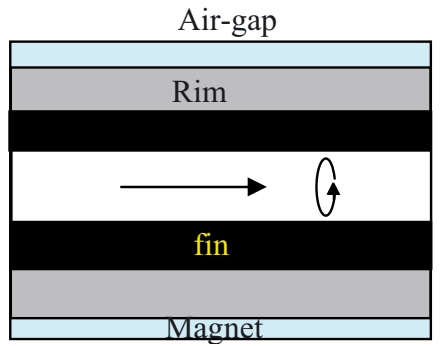

Axial view

Fig. 32. Rotor with triangular longitudinal fins.

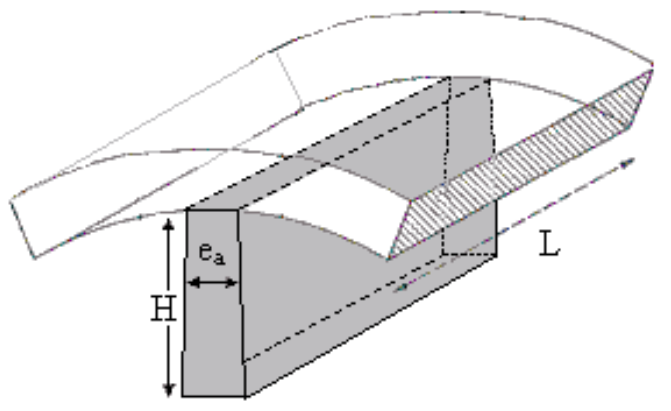

Fig. 33. Piece of the rotor with a fin.

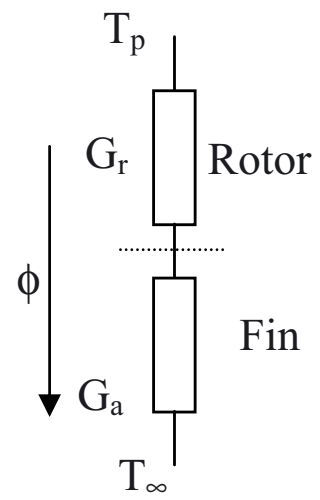

Fig. 34. Equivalent scheme.

are parallel to the direction of the airflow rate. The following heat balance can then be written:

$$
\begin{aligned}
\phi & =h S_{\mathrm{r}}\left(T_{\mathrm{p}}-T_{\infty}\right)+\eta h S_{\mathrm{m}}\left(T_{\mathrm{p}}-T_{\infty}\right) \\
& =\left(G_{\mathrm{r}}+G_{\mathrm{a}}\right)\left(T_{\mathrm{p}}-T_{\infty}\right)
\end{aligned}
$$

In this last equation, $S_{\mathrm{r}}$ is the contact surface between the rotor and the air and $S_{\mathrm{m}}$ referred to the wetted surface of the fin. The part of the rotor with fin, presented in Figure 33, can be thermally modeled as two conductances (series association) $G_{\mathrm{a}}$ and $G_{\mathrm{r}}$. The first one refers to the fin contribution and the other one to the rotor without fin contribution (Fig. 34).

The role of the fins is to dissipate the (thermal) energy of the rotor as well as ensuring a quite good compromise between its thermal and aeraulic performance,

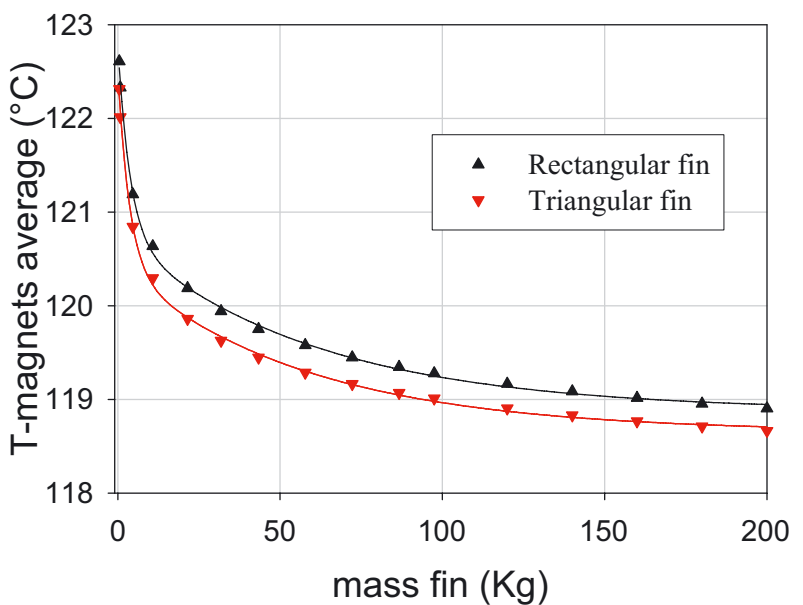

Fig. 35. Evolution of the magnet temperature with the mass of the fin.

its mass and its cumbersome. $G_{\mathrm{a}}$ is related to both the geometrical characteristics and the thermal fin conductivity. It depends on the three following quantities: the thermal conductivity of the fin $(\lambda)$, its thickness $\left(e_{\mathrm{a}}\right)$ and its width $H$. The heat transfer coefficient $h_{i}$ is assumed as constant. For considerations connected with the fin installation, 30 fins were used (one fin per magnet). Taking into account rotor dimensions and this fin number, the sizes of the fins are limited by $e_{\mathrm{a}}<\frac{2 \pi R_{i}}{30}=0.0869 \mathrm{~m}$ and $H<R_{i}=0.415 \mathrm{~m}$. To determine the optimal fin profile, in term of magnet cooling, two kinds of fins were analyzed: rectangular crossed section fins and triangular ones. The thermal equivalent scheme, the conductance and the efficiency of each considered fin are gathered in Table 9.

Figure 35 plots the variation of the averaged magnet temperature versus the fins mass for the two considered fin profiles. The plots have similar decreasing trends and let conclude that for an imposed fin mass, the triangular fins are more efficient in terms of cooling than the rectangular ones.

Figure 36 plots the variation of the averaged magnet temperature versus the conductance $G_{\mathrm{a}}$. This figure shows that the fin presence entails a reducing in the magnet temperature. The greater the fin conductance is, the lower the magnet temperature. 
Table 9. Fin profile.

\begin{tabular}{lc|c}
\hline Fin profile & Rectangular fin & Triangular fin \\
\hline Scheme & $G_{\mathrm{rc}}=\eta_{\mathrm{rc}} h L\left(e_{\mathrm{a}}+2 H\right)$ & $G_{\mathrm{tr}}=\eta_{\mathrm{tr}} h \frac{2 H L}{\cos (\alpha)}$ \\
Conductance & \\
Efficiency [24] & $\eta_{\mathrm{rc}}=\frac{e_{\mathrm{a}}}{\delta\left(e_{\mathrm{a}}+2 L\right)} \frac{(1+\delta) \exp (\chi H)-(1-\delta) \exp (-\chi H)}{(1+\delta) \exp (\chi H)+(1-\delta) \exp (-\chi H)}$ & $\eta_{\mathrm{tr}}=\frac{1}{\tau \sqrt{H}} \frac{I_{1}(2 \tau \sqrt{H})}{I_{0}(2 \tau \sqrt{H})}$ \\
\hline
\end{tabular}

with $\delta=\sqrt{\frac{h e_{\mathrm{a}}}{2 \lambda}}, \chi=\sqrt{\frac{2 h}{\lambda e_{\mathrm{a}}}}$ et $\tau=\sqrt{\frac{2 H h}{e_{\mathrm{a}} \lambda \cos (\alpha)}}$

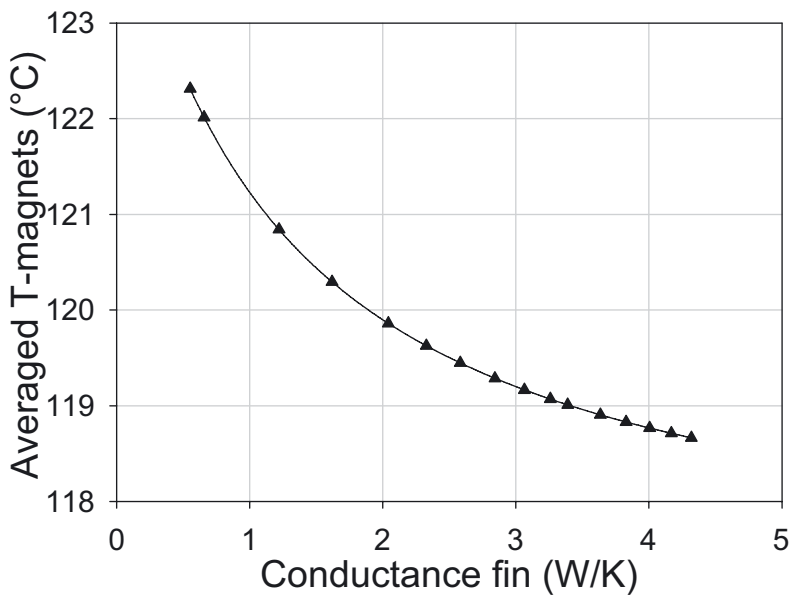

Fig. 36. Evolution of the magnet temperature with the conductance of the fin.

Aiming at reduce the technical problems involved by the manufacture and the installation of the fins (economic and cumbersome considerations), minimal size of the fins ensuring the suitable magnet cooling is seek. To identify the optimal mass value which entails a maximal heat exchange, the reduced sensibility coefficient $S_{\mathrm{m}}$ was investigated. This coefficient is defined as:

$$
S_{\mathrm{m}}=m\left|\frac{\partial T_{\text {aimant }}}{\partial m}\right|
$$

Figure 37 plots the evolution of $S_{\mathrm{m}}$ versus the mass of the fin. This reduced sensibility is maximal for a fin mass $m$ equal to about $4 \mathrm{~kg}$. The correlations of Vriendt [24] let obtain the optimal pair $\left(e_{\mathrm{a}}, H\right)$ for a given mass. These 2 correlations are written below:

$$
\begin{aligned}
\frac{H}{e_{\mathrm{a}}} & =0.6547 \sqrt{\frac{2 \lambda}{h e_{\mathrm{a}}}} \\
m & =0.5 \rho H e_{\mathrm{a}} L=4.1 \mathrm{~kg}
\end{aligned}
$$

Using these two correlations, the optimal pair $\left(e_{\mathrm{a}}, H\right)$ is obtained. The retained configuration is a rotor with 30 steel triangular fins, $3 \mathrm{~mm}$ thick and $75 \mathrm{~mm}$ width.

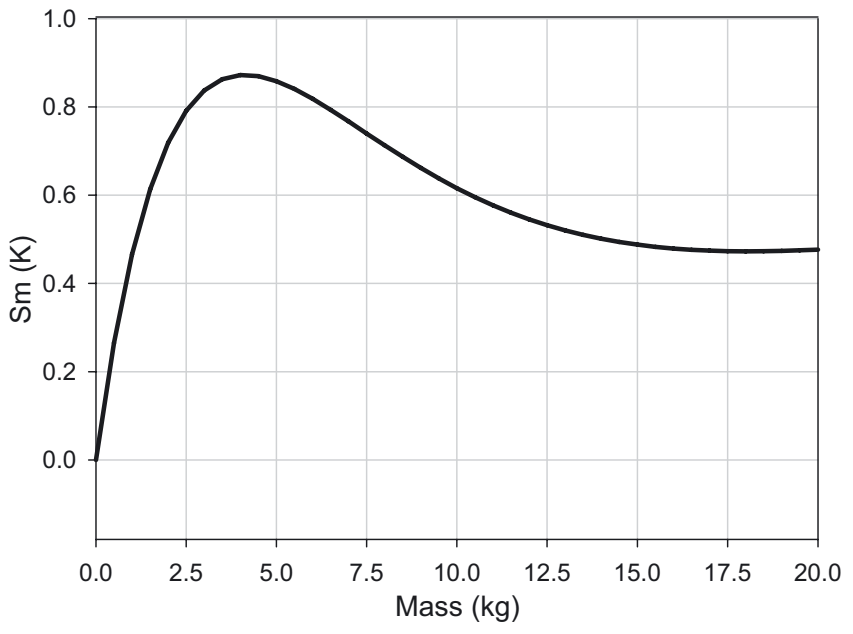

Fig. 37. Reduced sensibility of $T$-magnets to the mass of the fin.

The axial temperature evolution of the magnets for the different airflow rates and fin configurations (with or without) is plotted in Figure 38. The reference case namely smooth rotor with an axial airflow rate equals to $Q_{\mathrm{m}}=0.18 \mathrm{~kg} . \mathrm{s}^{-1}$, the case where the airflow rate inside a smooth rotor is $0.72 \mathrm{~kg} \cdot \mathrm{s}^{-1}$ and a case where the airflow rate inside a rotor with fins is $0.59 \mathrm{~kg} . \mathrm{s}^{-1}$ are studied. Even if the fins do not entail a real enhancement, they improve the magnet cooling for reasonable airflow rate: $Q_{\mathrm{m}}=0.59 \mathrm{~kg} . \mathrm{s}^{-1}$.

\subsection{Heat exchanger}

The magnet temperature lowering can also be obtained by enhancing the inner air temperature flowing into the rotor. An auxiliary empty pipe placed into the rotor and acting as a heat exchanger (with for instance water as cooling agent) can ensure this function. The axial airflow into the rotor is then cooled down. The chosen pipe is a $2.3 \mathrm{~m}$ length pipe corresponding to the iron length of the machine and is made of steel. It is $5 \mathrm{~mm}$ thick, and its inner diameter is $100 \mathrm{~mm}$ (Fig. 39). This 


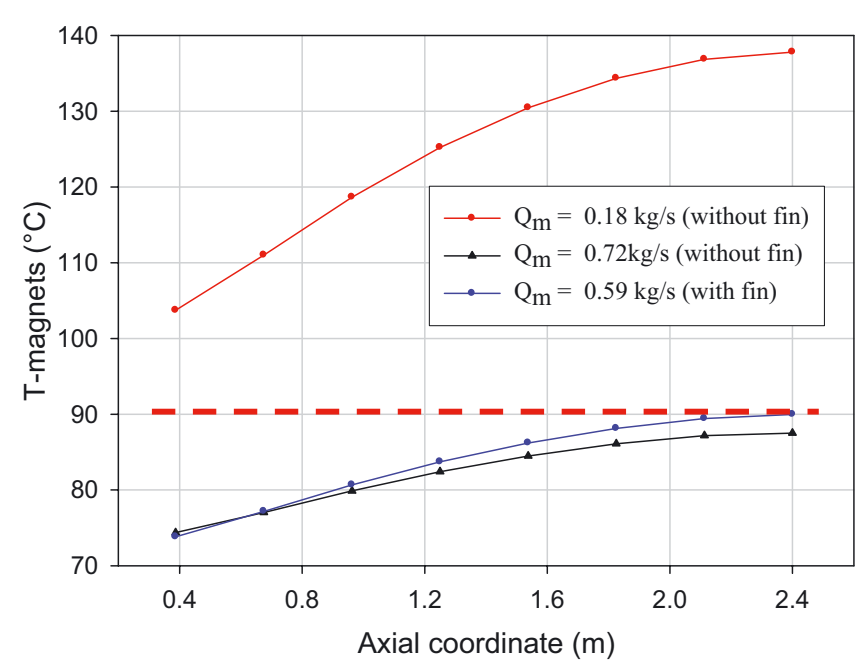

Fig. 38. Axial evolution of the magnet temperature.

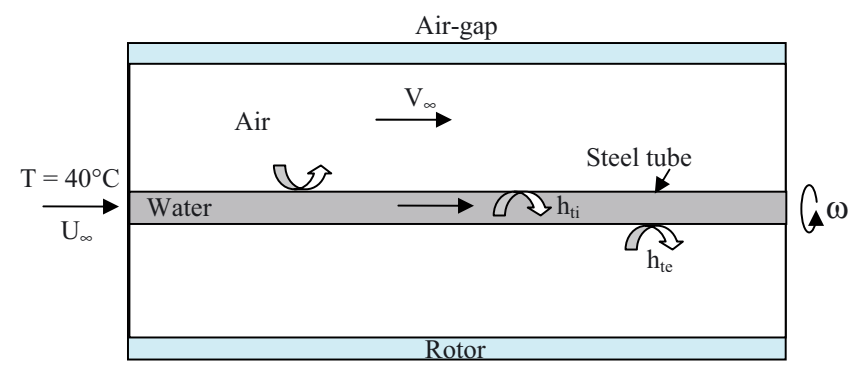

Fig. 39. Rotor with a static water cooling tube.

thickness lets obtain both the suitable thermal efficiency and the correct mechanical resistance. Figure 40 presents the equivalent thermal network suitable for such a configuration. The nodal resolution needs the identification of the convective heat transfer coefficients $h_{\mathrm{ti}}$ and $h_{\mathrm{te}} . h_{\mathrm{ti}}$ corresponds to the convective heat transfer coefficient between the wall and the cooling agent flowing into the pipe (water) and $h_{\text {te }}$ is the one between the wall and the inner air into the rotor.

The convective heat transfer coefficient between the water and the internal surface of the pipe is calculated using the following correlation of Mc Adams [19] adapted to the forced convection in turbulent pipe flow. This correlation takes into account the geometry via the ratio $L / D_{t}$.

$$
\begin{aligned}
N u & =0.023 P r^{0.33}\left(1+\left(\frac{D_{\mathrm{t}}}{L}\right)^{0.7}\right) R e^{0.8} \\
\text { and } \quad R e & =\frac{D_{\mathrm{t}} U_{\infty}}{\nu_{\text {water }}}
\end{aligned}
$$

This correlation remains valid for a Prandtl number ranging between 0.7 and 100, an axial Reynolds number ranging from $10^{4}$ and $1.2 \times 10^{5}$. Using this relation in the studied case, the heat transfer coefficient is:

$$
h_{\mathrm{ti}}=\frac{\lambda_{\text {water }} N u}{D_{\mathrm{t}}}=23511 \mathrm{~W} \cdot \mathrm{m}^{-2} \cdot \mathrm{K}^{-1}
$$

The flow outside the pipe results from the coupling of the air driven into rotation by the rim of the rotor (viscous effects) and the axial airflow into the rotor. It is difficult to identify the convective heat transfer coefficient, since no correlations corresponding to this specific case have been found. However, two cases of heat transfer are relatively similar to this problem. These two cases are presented thereafter and concern the case of the free convection around a horizontal tube and the case of the rotating pipe in still air.

\subsubsection{Free convection around a horizontal tube}

As the rotor diameter is considerable $(D i=830 \mathrm{~mm})$ and the airflow velocity very low, $V_{\infty}=0.3 \mathrm{~m} . \mathrm{s}^{-1}$, the convective transfer can be assumed in a first approach as controlled by laws of free convection. It thermally represents the worse case. The Nusselt number is then estimated using the following Mc Adams correlation [19] based on the Rayleigh number:

$$
N u=0.53 R a^{0.25} \text { for } 10^{4}<R a<10^{9}
$$

To evaluate $N u$ and $R a$ the reference geometrical quantity is the pipe diameter. Then $R a=9.4 \times 10^{5}$ and $h_{\mathrm{te}}=4.3 \mathrm{~W} \cdot \mathrm{m}^{-2} \cdot \mathrm{K}^{-1}$. Other thermo-physic quantities are taken at the film temperature, i.e. $\left(T_{\mathrm{p}}+T_{\infty}\right) / 2 . T_{\infty}$ is the averaged air temperature into the rotor and is obtained using an iterating process and the previous model.

\subsubsection{Rotating pipe into still air}

In this second case, the air driven into rotation by the rotor rim controls the convective heat transfer. Many correlations exist in the case of rotating pipe in still air. If it is assumed that the heat transfers are not too different in both cases, value for the convective heat transfer coefficient can be obtained. For instance, the Becker correlation [25] presented thereafter lets obtain a value for this quantity. This correlation can be written as:

$N u=0.133 \operatorname{Re}^{0.66} \operatorname{Pr}^{0.33}$ with $\quad 800<R e=\frac{\omega D^{2}}{2 \nu}<10^{5}$

Using the physical properties of the air taken at the film temperature $\left(T_{\mathrm{P}}+T_{\infty}\right) / 2$, the Reynolds number is equal to $R e_{\mathrm{r}}=\frac{\omega D^{2}}{2 \nu}=7.4 \times 10^{3}$, and then $h_{\mathrm{te}}=$ $11.5 \mathrm{~W} \cdot \mathrm{m}^{-2} \cdot \mathrm{K}^{-1}$.

The results plotted in Figure 41 correspond to the axial evolution of the magnet temperature for both the configurations (with and without pipe). For the case with the pipe, the magnet temperature is evaluated using $h_{\mathrm{ti}}$ calculated with the both assumptions made previously. The presence of the pipe enhances considerably the heat transfer resulting in a magnet temperature decreasing. The losses in the rotor are transferred to the internal airflow and then to water flowing into the tube. It involves a considerable enhancement of the heat transfer between the rotor and the air. The results obtained with the model show that the use of this kind of technique lowers the magnet temperature of $44{ }^{\circ} \mathrm{C}$ if $h_{\text {it }}=4.3 \mathrm{~W} \cdot \mathrm{m}^{-2} \cdot \mathrm{K}^{-1}$ (first 


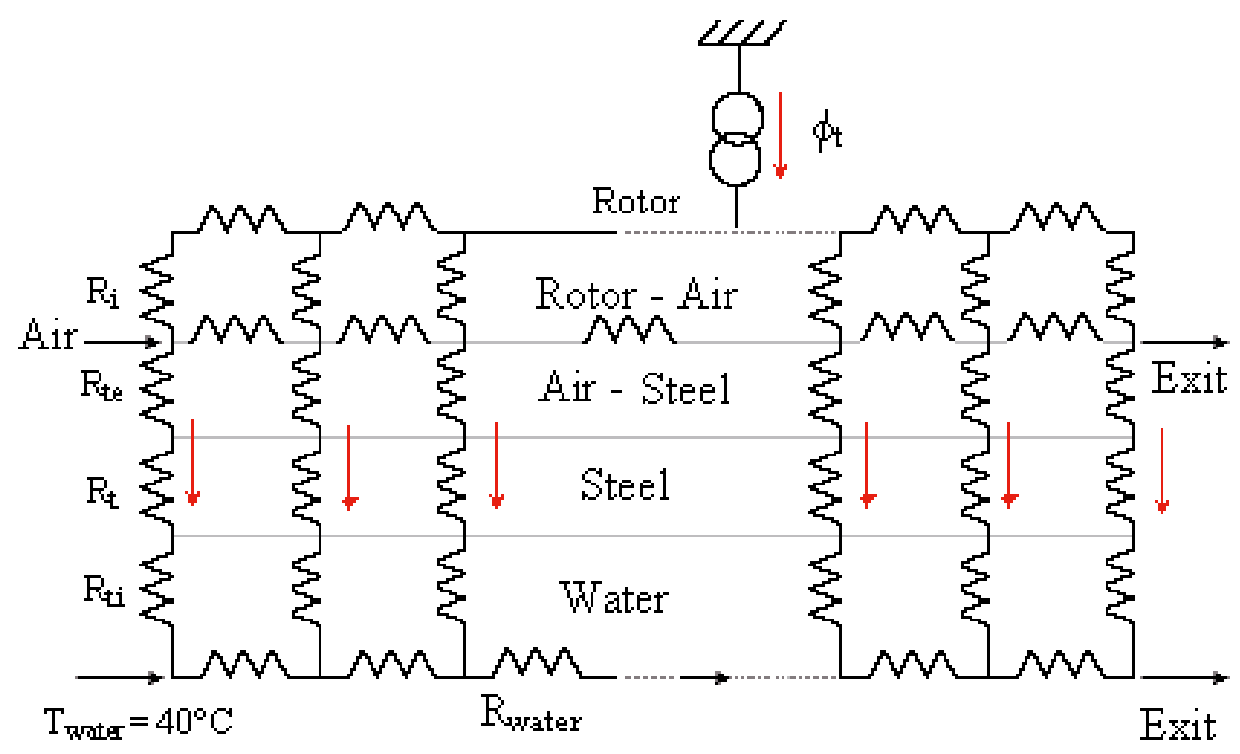

Fig. 40. Equivalent scheme.

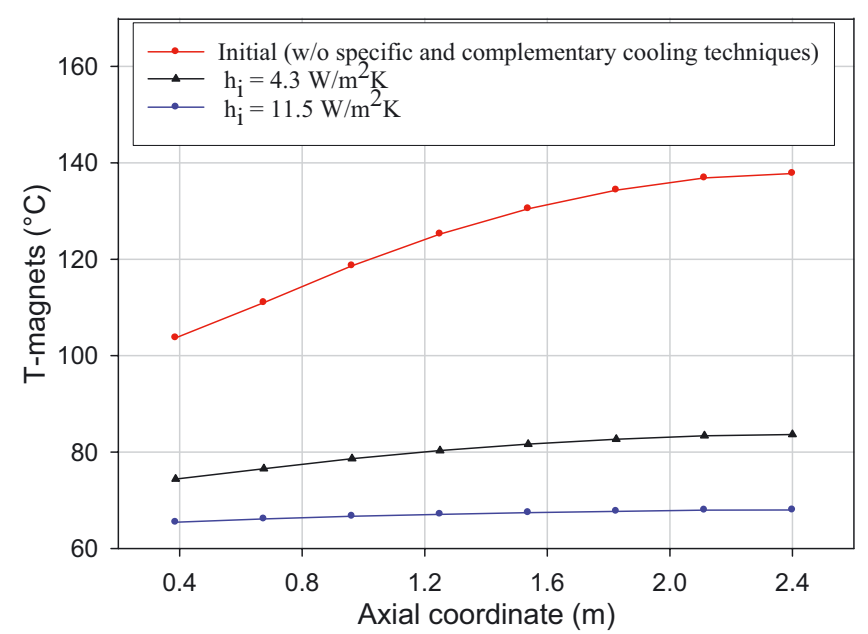

Fig. 41. Axial evolution of the magnet temperature.

assumption) and $57{ }^{\circ} \mathrm{C}$ if $h_{\text {it }}=11.5 \mathrm{~W} \cdot \mathrm{m}^{-2} \cdot \mathrm{K}^{-1}$ (second assumption). This technique is very interesting in a POD configuration since it does not require the use of an additional heat exchanger to cool down the water flowing into the pipe (direct use of the sea water).

Among the machine architectures interesting Jeumont S.A-Areva, the case of the self-ventilated machines can be quoted. They are perfectly waterproof and do not require any external forced ventilation. This kind of architecture is often used in the high rotational speed machines. However, it can be interesting to analyze the influence of no airflow rate on the thermal behavior of the studied machine even if it is driven at lower rotation speed ( $\omega=250 \mathrm{rpm})$. Figure 42 shows the axial evolution of the magnet temperature in a configuration without inner airflow. The plot shows the cooling is highly improved when compared to the reference configuration. With this

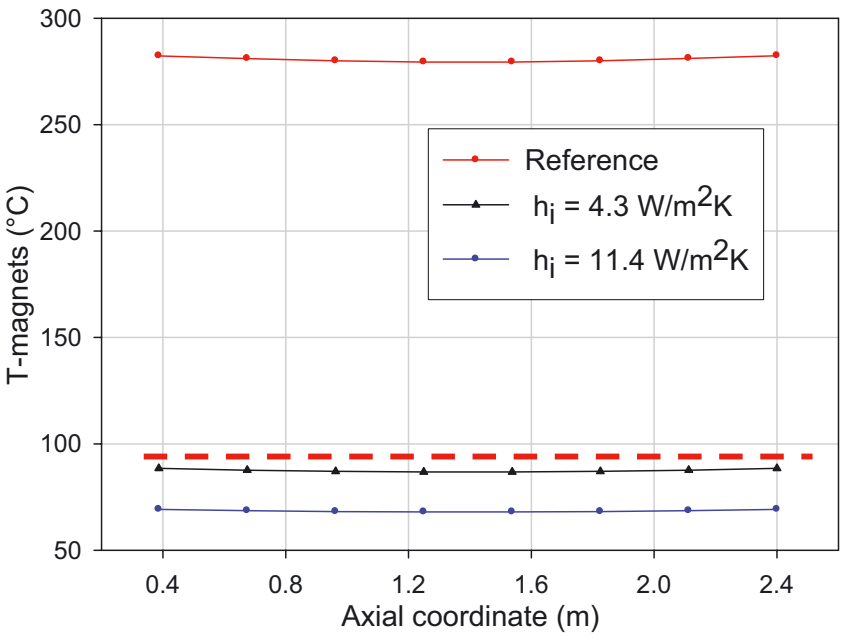

Fig. 42. Axial evolution of the magnet temperature without mass flow rate.

technique and despite the airflow withdrawal, the temperatures are lowered and remain within the thermal operating conditions. This auxiliary tube is thus an efficient solution to cool down this part.

\subsection{Thermal bridge}

The thermal behavior of the end-windings is quite weakly influenced by the inner aeraulics. To ensure a suitable cooling, the frame can be both connected to these end-windings and to the water using a copper thermal bridge as shown in Figure 43. The correct thermal connection between the end-windings and the thermal bridge is ensured using resin layers which is an electrical insulation but not a thermal one $\left(\lambda=5 \mathrm{~W} \cdot \mathrm{m}^{-1} \cdot \mathrm{K}^{-1}\right)$. The thickness 


\begin{tabular}{|c|c|c|c|}
\hline 45 & 40 & 40 & 40 \\
\hline 56 & & & \\
\hline 66 & & & \\
\hline 76 & & & \\
\hline 79 & & & \\
\hline 100 & 140 & 165 & $\mid 177$ \\
\hline 113 & 146 & 169 & 180 \\
\hline 119 & 150 & 172 & 182 \\
\hline 122 & & & \\
\hline 128 & 163 & 186 & \begin{tabular}{|l}
198 \\
\end{tabular} \\
\hline 130 & 164 & 187 & 198 \\
\hline 131 & 164 & 187 & 198 \\
\hline 126 & & & \\
\hline 123 & & & \\
\hline 137 & & & \\
\hline 137 & & & \\
\hline 129 & & & \\
\hline
\end{tabular}

Without thermal bridge

\begin{tabular}{|c|c|c|c|}
\hline 45 & 41 & 40 & 40 \\
\hline 54 & 42 & 41 & 41 \\
\hline 63 & 42 & 42 & 41 \\
\hline 72 & 42 & 42 & 42 \\
\hline 75 & 42 & 42 & 42 \\
\hline 89 & 81 & 80 & 79 \\
\hline 103 & 116 & 122 & 124 \\
\hline 112 & 135 & 146 & 151 \\
\hline 115 & 141 & 153 & 159 \\
\hline 121 & 148 & 161 & 167 \\
\hline 125 & 154 & 168 & 175 \\
\hline 126 & 157 & 171 & 179 \\
\hline 122 & \multicolumn{3}{|l}{} \\
\cline { 1 - 1 } 122 & \multicolumn{5}{|l}{} \\
\hline 136 & \multicolumn{5}{|l}{} \\
\cline { 1 - 1 } 136 & \multicolumn{5}{|l}{} \\
\cline { 1 - 1 } 127 &
\end{tabular}

With ring type thermal bridge

\begin{tabular}{|c|c|c|c|c|c|}
\hline 44 & 42 & 42 & 42 & 42 & 42 \\
\hline 52 & 44 & 44 & 44 & 45 & 45 \\
\hline 59 & 44 & 44 & 45 & 45 & 45 \\
\hline 67 & 45 & 45 & 45 & 46 & 46 \\
\hline 68 & 45 & 45 & 45 & 46 & 47 \\
\hline 80 & 65 & 60 & 57 & 50 & 47 \\
\hline 89 & 79 & 73 & 67 & 55 & 48 \\
\hline 94 & 85 & 78 & 72 & 57 & 49 \\
\hline 97 & 84 & 78 & 70 & 57 & 50 \\
\hline 101 & 91 & 84 & 76 & 59 & 50 \\
\hline 104 & 96 & 88 & 79 & 61 & 51 \\
\hline 105 & 96 & 88 & 78 & 61 & 51 \\
\hline 106 & 94 & 83 & 71 & 79 & 51 \\
\hline 116 & & & & & \\
\hline 132 & & & & & \\
\hline 131 & & & & & \\
\hline 123 & & & & & \\
\hline
\end{tabular}

With cylindrical type thermal bridge
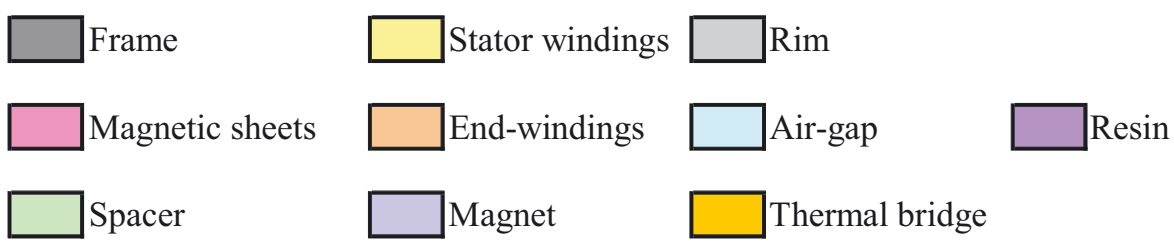

Fig. 43. Thermal behavior of the end-windings (temperatures in ${ }^{\circ} \mathrm{C}$ ).

of the resin layers ranges between 0.3 and $10 \mathrm{~mm}$. Using this solution, the quasi-motionless air playing an important thermal insulation role $\left(\lambda=0.025 \mathrm{~W} \cdot \mathrm{m}^{-1} \cdot \mathrm{K}^{-1}\right)$ is replaced by a material of greater thermal conductivity. The heat transfer from the end-windings towards the frame (through the thermal bridge) and the cooling water is then enhanced. Figure 43 also permits to compare the end-windings temperature in both cases, i.e. with and without the thermal bridge. It is clearly shown the bridge enhances the cooling. Indeed, with the thermal bridge, the heat transfer between the end-windings and the frame is improved since, for the end-windings, a reduction of $34^{\circ} \mathrm{C}$ in the average temperature is observed for the case of a crown type thermal bridge and a diminution of $95{ }^{\circ} \mathrm{C}$ for the case of a cylindrical type thermal bridge. The ring type bridge case is more efficient in the cooling of the upper part of the end-windings since a decrease of the average temperature equals to $49{ }^{\circ} \mathrm{C}$ can be noticed. However, the lower part of the end-windings is not significantly cooling and the temperature diminution in this part is lower than $18{ }^{\circ} \mathrm{C}$. Even if the heat transfer is enhanced, hot spots mainly located in the lower part exist. This remark shows the thermal bridge must still be improved in order to dissipate more heat. Choice of the cylindrical type bridges ended with a copper ring and covering with resin the whole end-windings is better. Indeed, in this case, the maximal end-windings temperature is $T_{\max }=96{ }^{\circ} \mathrm{C}$. No hot spots were observed. Due to this thermal bridge, the heat transfer from the end-windings towards the frame is intensified. The thermal energy of the end-windings is then evacuated outside and a significant temperature lowering is to note.

\section{Conclusion}

This work deals with a thermal study of a permanent magnets synchronous motor. A nodal approach was developed in order to simulate the thermal behavior of this machine. This model permits to better understand the thermal behavior, to limit the temperatures of the different components, and to predict the thermal response of the engine in extreme operating conditions. It also permits to design and develop new cooling systems. The results show that the hottest parts are located in the magnets and end-windings where the temperatures exceed the operational limits. A particular attention was focused on these parts in order to analyze their thermal behavior with the sensible parameters variation. These sensibility studies let propose technical cooling solutions able to ensure optimized temperature values in the whole machine. Several cooling solutions were investigated. In order to decrease in a significant way the magnet temperature, the interior of the rotor can be equipped with longitudinal fins. The use of an auxiliary pipe into the rotor operating as a heat exchanger is interesting to maintain the magnet temperature far from the critical temperature. The utilization of thermal bridges for the end-winding cooling lets improve the heat transfers and results in the decrease of the end-winding temperature. Implementation of these 
cooling solutions limits the temperatures into the whole machine to values lower than expected.

Acknowledgements. The authors gracefully thank the CNRT, the North-Pas-de-Calais district, and the French Minister of National Education for their financial support.

\section{References}

[1] W.W. Soroka, Analog methods in computation and simulation, Ed. McGraw Hill, 1954, p. 390

[2] J.B. Saulnier, La modélisation thermique et applications aux transferts couplés et au contrôle actif, Thèse de l'université de Poitiers, 1980

[3] J.B. Saulnier, A. Alexandre, La modélisation thermique par la méthode nodale : Ses principes, ses succès et ses limites, Rev. Gén. Therm. Fr 280 (1985) 363-372

[4] Y. Bertin, Analyse des transferts de chaleur dans un moteur électrique asynchrone, Développement d'un environnement $\mathrm{CAO}$ et modélisations thermoaréauliques, Thèse de l'université de Poitiers, 1987

[5] C. Vasilescu, Modélisation du transfert de chaleur au sein des machines électriques tournantes - dimensionnement et optimisation de leur système de refroidissement, Thèse de l'université de Paris VI, 2002

[6] F. Tachibana, S. Fukui, Convective heat transfer of the rotational an axial flow between two concentric cylinders, Bull. JSME 7 (1964) 385-391

[7] P.R.N. Childs, A.B. Turner, Heat transfer on the surface of a cylinder rotating in an annulus at high axial and rotational Reynolds numbers, Congres Brighton, 1994

[8] M. Bouafia, Y. Bertin, J.B. Saulnier, Analyse expérimentale des transferts de chaleur en espace annulaire étroit et rainuré avec cylindre intérieur tournant, Int. J. Heat Mass Trans. 41 (1998) 1279-1291

[9] I. Peres, Y. Bertin, Caractérisation des échanges de chaleur dans un espace annulaire lisse et rainuré de type entrefer moteur électrique, Société française des thermiciens, 1994
[10] M. Bouafia, A. Ziouchi, Y. Bertin, J.B. Saulnier, Étude expérimentale et numérique des transferts de chaleur en espace annulaire sans débit axial et avec cylindre intérieur tournant, Int. J. Therm. Sci. (1999) 547-559

[11] J. Gosse, Guide technique de thermique, Dunod Paris, 1981, pp. $168-169$

[12] G. Reich, Strömung und wärmeübertragung in einem axial rotierenden Rohr, Doctoral Thesis, TH Darmstadt, 1988

[13] G. Reich, B. Weigand, H. Beer, Fluid flow and heat transfer in an axially rotating pipe-II. Effect of rotation on laminar pipe flow, Int. J. Heat Mass Tran. 32 (1989) 563-574

[14] J.N. Cannon, W.M. Kays, Heat transfer to a fluid flowing inside a pipe rotating about its longitudinal axis, J. Heat Transfer. 91 (1969) 135-139

[15] G. Reich, H. Beer, Fluid flow and heat transfer in an axially rotating pipe-I. Effect of rotation on turbulent pipe flow, Int. J. Heat Mass Tran. 32 (1989) 551-562

[16] B. Weigand, H. Beer, Fluid flow and heat transfer in an axially rotating pipe subjected to external convection, Int. J. Heat Mass Tran. 35 (1992) 1803-1809

[17] S. Seghir-Ouali, D. Saury, S. Harmand, O. Phillipart, D. Laloy, Convective heat transfer inside a rotating cylinder with axial air flow, Int. J. Therm. Sci., in press

[18] Fluent v.6.0, User's guide, 2001

[19] W.H. Mc Adams, Transmission de la chaleur, Dunod Paris, 1961

[20] M. Fishenden, O.A Saunders, An introduction to heat transfer, Oxford, 1950

[21] F. Kreith, Convection heat transfer in rotating systems, T.F. Irvine, J.P. Hartnett (Eds.), 1968, Vol. 21

[22] C.Z.O. Popiel, L. Boguslawski, Local heat transfer coefficients on the rotating disk in still air, Int. J. Heat Mass Trans. 18 (1975) 167-170

[23] A. Bontemps, Échangeur de chaleur, Description des échangeurs. Techniques de l'ingénieur, B2 341, 1995

[24] A.B. De Vriendt, La transmission de la chaleur, G. Morin (éd.), 1984, Vol. I, tome 1

[25] K.M. Becker, Measurement of convective heat transfer from a horizontal cylinder rotating in a tank of water, Int. J. Heat Mass Trans. 6 (1963) 1053-1062 